\title{
A Feasibility Study of Oil Shale Fired Pulse Combustors With Applications to Oil Shale Retorting
}

Final Report

Gary J. Morris

Eric K. Johnson

Guo Q. Zhang

Robert Allen Roach

Work Performed Under Contract No.: DE-FG21-90MC27401

\author{
For \\ U.S. Department of Energy \\ Office of Fossil Energy \\ Morgantown Energy Technology Center \\ P.0. Box 880 \\ Morgantown, West Virginia 26507-0880 \\ West Virginia University \\ Mechanical and Aerospace Engineering \\ P.O. Box 6101 \\ Morgantown, West Virginia 26506
}

July 1992 


\section{ABSTRACT}

The results of the experimental investigation performed to determine the feasibility of using pulverized Colorado oil shale to fuel a bench scale pulse combustor reveal that oil shale cannot sustain pulsations when used alone as fuel. Trace amounts of propane mixed with the oil shale enabled the pulsations, however. Up to $80 \%$ of the organic material in the oil shale was consumed when it was mixed with propane in the combustor. Beyond the feasibility objectives, the operating conditions of the combustor fuel with propane and mixtures of oil shale and proparis were characterized with respect to pulsation amplitude and frequency and the internal combustor wall temperature over fuel lean and fuel rich stoichiometries. Maximum pressure excursions of $12.5 \mathrm{kPa}$ were experienced in the combustor. Pulsation frequencies ranged from 50 to nearly $80 \mathrm{~Hz}$. Cycle resolved laser Doppler anemometry velocities were measured at the tail pipe exit plane. Injecting inert mineral matter (limestone) into the pulse combustor while using propane fuel had only a slight effect on the pulsation frequency for the feed rates tested. 
ABSTRACT

TABLE OF CONTENTS

LIST OF FIGURES

INTRODUCTION

LITERATURE REVIEW

EXPERIMENTAL IPPARATUS

RESULTS

CONCLUSIONS

REFERENCES

APPENDICES
11

iil

Iv

$1=$

3

5

13

31

32

33 
$\begin{array}{ll}\text { Figure 1. Pulse Combustor Design } & 6\end{array}$

Figure 2. Cone Arrangement Inside Combustion Chamber 6

Figure 3. Conditioned Sampling with Ensemble-Averaging Process 11

Figure 4. Schematic Diagram for the Conditioned Sampling Trigger 11 Circuitry.

Figure 5. Pressure Excursions for the Propane Fired Pulse Combustor 15 $(\phi=0.6$, Tail pipe $=4 \mathrm{ft}, 1.22 \mathrm{~m})$.

Figure 6. Time Dependent Tail Pipe Velocities for the Propane Fired Pulse Combustor $(\phi=0.6$, Tail pipe $=4 \mathrm{ft}, 1.22 \mathrm{~m})$

Figure 7. Pressure Excursions for the Propane Fired Pulse Combustor $(\phi=0.8$, Tail pipe $=4 \mathrm{ft}, 1.22 \mathrm{~m})$.

Figure 8. Time Dependent Tail Pipe Velocities for the Propane Fired 16 Pulse Combustor $(\phi=0.8$, Tail pipe $=4 \mathrm{ft}, 1.22 \mathrm{~m})$

Figure 9. Pressure Excursions for the Propane Fired Pulse Combustor $(\phi=1.0$, Tail pipe $=4 \mathrm{ft}, 1.22 \mathrm{~m})$.

Figure 10. Time Dependent Tail Pipe Velocities for the Propane Fired Pulse Combustor $(\phi=1.0$, Tail pipe $=4 \mathrm{ft}, 1.22 \mathrm{~m})$

Figure 11. Pressure Excursions for the Propane Fired Pulse Combustor $(\phi=1.2$, Tail pipe $=4 \mathrm{ft}, 1.22 \mathrm{~m})$.

Figure 12. Time Dependent Tail Pipe Velocities for the Propane Fired Pulse Combustor $(\phi=1.2$, Tail pipe $=4 \mathrm{ft}, 1.22 \mathrm{~m})$

Figure 13. Pressure Excursions for the Propane Fired Pulse Combustor $(\phi=1.4$, Tail pipe $=4 \mathrm{ft}, 1.22 \mathrm{~m})$.

Figure 14. Time Dependent Tail Pipe Velocities for the Propane Fired Pulse Combustor $(\phi=1.4$, Tail pipe $=4 \mathrm{ft}, 1.22 \mathrm{~m})$

Figure 15. Pressure Excursions for the Propane Fired Pulse Combustor $(\phi=0.6$, Tail pipe $=2 \mathrm{ft}, 0.61 \mathrm{~m})$.

Figure 16. Time Dependent Tail Pipe Velocities for the Propane Fired Pulse Combustor $(\phi=0.6$, Tail pipe $=2 \mathrm{ft}, 0.61 \mathrm{~m})$

Pressure Excursions for the Propane Fired Pulse Combustor $(\phi=0.8$, Tail pipe $=2 \mathrm{ft}, 0.61 \mathrm{~m})$.

Figure 18. Time Dependent Tail Pipe Velocities for the Propane Fired Pulse Combustor $(\phi=0.8$, Tail pipe $=2 \mathrm{ft}, 0.61 \mathrm{~m})$

Figure 19. Pressure Excursions for the Propane Fired Pulse Combustor $(\phi=1.0$, Tail pipe $=2 \mathrm{ft}, 0.61 \mathrm{~m})$. 
Figure 20. Time Dependent Tail Pipe Velocities for the Propane Fired Pulse Combustor $(\phi=1.0$, Tail pipe $=2 \mathrm{ft}, 0.61 \mathrm{~m})$

Figure 21. Pressure Excursions for the Propane Fired Pulse Combustor $(\phi=1.2$, Tail pipe $=2 \mathrm{ft}, 0.61 \mathrm{~m})$.

Figure 22. Time Dependent Tail Pipe Velocities for the Propane Fired Pulse Combustor $(\phi=1.2$, Tail pipe $=2 \mathrm{ft}, 0.61 \mathrm{~m})$

Figure 23. Pressure Excursions for the Propane Fired Pulse Combustor $(\phi=1.4$, Tail pipe $=2 \mathrm{ft}, 0.61 \mathrm{~m})$.

Figure 24. Time Dependent Tail Pipe Velocities for the Propane Fired Pulse Combustor $(\phi=1.4$, Tail pipe $=2 \mathrm{ft}, 0.61 \mathrm{~m})$

Figure 25. Effect of Equivalence Ratio on Maximum Pressure Excursions for the Propane Fired Pulse Combustor (Tail pipe $=4 \mathrm{ft}$, $1.22 \mathrm{~m}$ ).

Figure 26. Effect of Equivalence Ratio on Pulsation Frequency for the Propane Fired Pulse Combustor (Tail pipe $=4 \mathrm{ft}, 1.22 \mathrm{~m}$ ).

Figure 27. Effect of Equivalence Ratio on Maximum Pressure Excursions for the Propane and Oil Shale Fired Pulse Combustor (Tail pipe $=4 \mathrm{ft}, 1.22 \mathrm{~m}$ ).

Figure 28. Effect of Equivalence Ratio on Pulsation Frequency for the Propane and Oil Shale Fire Pulsed Combustor (Tail pipe $=4$ ft, $1.22 \mathrm{~m}$ ).

Figure 29. Effect of Equivalence Ratio on the Internal Wall Temperature for the Propane and Oil Shale Fire Pulsed Combustor (Tail pipe $=4 \mathrm{ft}, 1.22 \mathrm{~m}$ ). 


\section{INTRODUCTION}

Pulse combustion technology has evolved slowly over the past several decades with several aspects of the operating principles eluding numerous investigators. Even so, scientists and engineers have made effective use of the high combustion intensity associated with pulse combustors. Pulse combustors have been used in applications such as propulsion systems, residential heating, drying of various particulate matter, and coal gasification. The advantages of pulsating combustion include a high combustion efficiency, a high combustion intensity, and a high convective heat transfer rate to fuel particles and to the combustor surfaces.

The application of pulsed combustion described within this report is to determine the feasibility of using pulverized oil shale to fuel a pulse combustor. While fueling a pulse combustor with solid fuels such as coal is not new, the concept of using oil shale as fuel shows promise towards being able to use a pulse combustor to drive an oil shale retort to extract useful hydrocarbon fuel. Utilizing a pulse combustor in this manner could eventually lead to oil shale retorting near the extraction site which would eliminate the costly need to transport the unusable mineral matter that is associated with raw oil shales. This potential scenario would also eliminate the need to supply a secondary fuel to provide the thermal energy to drive the retort.

The significant technical advantages of the periodically pulsed gas flow through an oil shale retort include enhanced heat and mass transfer between the oil shale particles and the driving gases. The particle residence time in the pulsed retort will be increased compared to steady flow retorts. All of these advantages should result in increased fuel recovery efficiency for 
the pulsed retort.

The main objective of this feasibility study was to determine if raw oil shale could be effectively used as a solid fuel for an existing pulse combustor geometry design. A brief fundamental investigation was performed using a propane with pulverized limestone injected into the combustor at a known mass flow rate in order to determine the effect of the inert material on the combustor performance.

A second objective of the proposed research program was to characterize the operation of the pulse combustor fueled on pulverized oil shale with regard to amplitude and frequency of the pressure pulses, and the combustion chamber temperature. The behavior of the pulse combustor was more fully explored using propane as fuel due to the ease of fuel handling and relatively clean exhaust stream. Also laser Doppler anemometry velocity measurements were performed while using propane as fuel. The oil shale combustion caused major problems with the laser velocity measurements due to the exhaust stream residue obscuring the optical access ports. 


\section{LITERATURE REVIEW}

The literature contains several accounts of solid fueled pulse combustion and gasification, however, the applications of such combustors to oil shale retorting are unknown to the authors.

Belter et al [1] performed an experimental investigation of a pulverized lignite fueled, valveless pulse combustor to dry batches of lignite. The lignite required co-firing with a small amount $16 \%$ of the total energy released by the combustor) of heavy fuel oil to yield acceptable performance. The castable refractory lined combustion chamber remained intact during the combustion process of the solid fuel.

Zinn et al [2] experimented with the concept of burning unpulverized coal in a Rijke type pulse combustor. The combustor consisted of a vertical tube open on both ends with a coal bed positioned close the bottom end. The energy released by the stationary coal bed excited the natural frequency of the tube causing acoustic oscillations which intensified the combustion. An important discovery of this work is that both fuel rich and fuel lean conditions were possible in the forced mode of operation. The rich mode would be applicable to coal gasification or oil shale retorting due to its depletion of molecular oxygen from the exhaust gases.

Carvalho et al [4] experimented with a very similar vertical pulse combustor as did Zinn [2]. Using unpulverized coal as fuel, combustion efficiencies higher than $95 \%$ were found while operating with as little as $13 \%$ excess air. It was also found that NOx production could be controlled by staging the combustion in the vertical tube.

Traenckner [5] attempted coal gasification using a pulse combustor with pulverized coal as fuel. The preliminary results showed that the process was feasible with a modest gas efficiency of $63 \%$ and a carbon conversion of 93\% with preheated reactants. The results suggested that lignite performed 
better than bituminous coal based on the gas efficiency and the carbon conversion percentages.

Durai-Swamy and Warren [6] tested the feasibility of using pulse combustors to gasify waste materials such as paper mill sludge waste, pistachio shells, wood chips, and rice hulls. Utilizing the indirect heating process whereby the material to be gasified receives thermal energy through heat transfer from the external surfaces of a combustor, Durai-Swamy and Warren report that tests conducted at MTCI on the biomass specimens proved successful. The mild gasification produced a medium BTU gas (370-410 BTU/SCF) while capable of receiving a variety of feed stock variations including those with a large moisture content.

Sommers [7] reports the results of pulsed combustion gasification of brown coal at a Ruhrgas test plant. The method described used direct heating of the feed stock to be gasified by using it to also fuel the pulse combustor. The excess solid fuel within the combustor absorbed some the thermal energy released by the combustion of the coal and the volatiles and, therefore, underwent gasification processes in the oxygen depleted environment. Gasification efficiencies up to $63 \%$ percent were reported without the recycling of unconsumed coal dust which would increase the efficiency.

Powell et al [8] performed an experimental study using a quarter wave pulse combustor for the gasification of 70 micron lignite particles. The combustor pulsed at approximately $90 \mathrm{~Hz}$. Prior to fueling the combustor with coal, it had to be preheated using natural gas. Powell reports little effect of pulsations on the concentrations of the major constituents of the products gas with the exception of sulfur dioxide which was significantly reduced. 


\section{EXPERIMENTAL APPARATUS}

The first phase of the experimental investigation involved designing and constructing a bench scale pulse combustor to burn solid fuels. To minimize design risks, the combustor was designed similarly to proven devices [3] that burn pulverized solid fuels. The tail pipe length was varied to determine the effect on the performance of the combustor.

The second phase involved fueling the combustor with pulverized oil shale to test the feasibility of using a pulse combustor to provide the thermal energy and gas volume flow to drive an upward flowing entrained reactor retort. The combustor was designed with the capability of using propane since the combustor needed to be preheated prior to using oil shale as fuel.

\section{PHASE I - Design and Construction of the Combustor and the Fuel Feeder}

The pulse combustor design included no moving parts to wear or foul during the harsh combustion environment. The combuster (Figure 1) consisted of a horizontally mounted combustion chamber body modeled after the design of Katsnel'son et al [3] with modular tail pipe geometries that were easily removed to test the performance of various lengths. In order to accurately measure the equivalence ratio for each test, the inlet to the combustor was connected to an air supply line. Self-aspirating, aerovalved pulse combustors do not lend themselves to accurate measurement of the volume flow rate of air ingestion. The fuel inlet was a concentric tube arrangement as shown in Figure 2. The pulverized oil shale flowed along the central port of the tube while the propane fuel flowed along the annular passage. Combustion air entered a tee connection as shown in Figure 1 and it also flowed in an outer annular passage toward the combustor. A 20 gauge stainless steel cone $4.45 \mathrm{~cm}$ in diameter was positioned at the end of the fuel injection tube in 

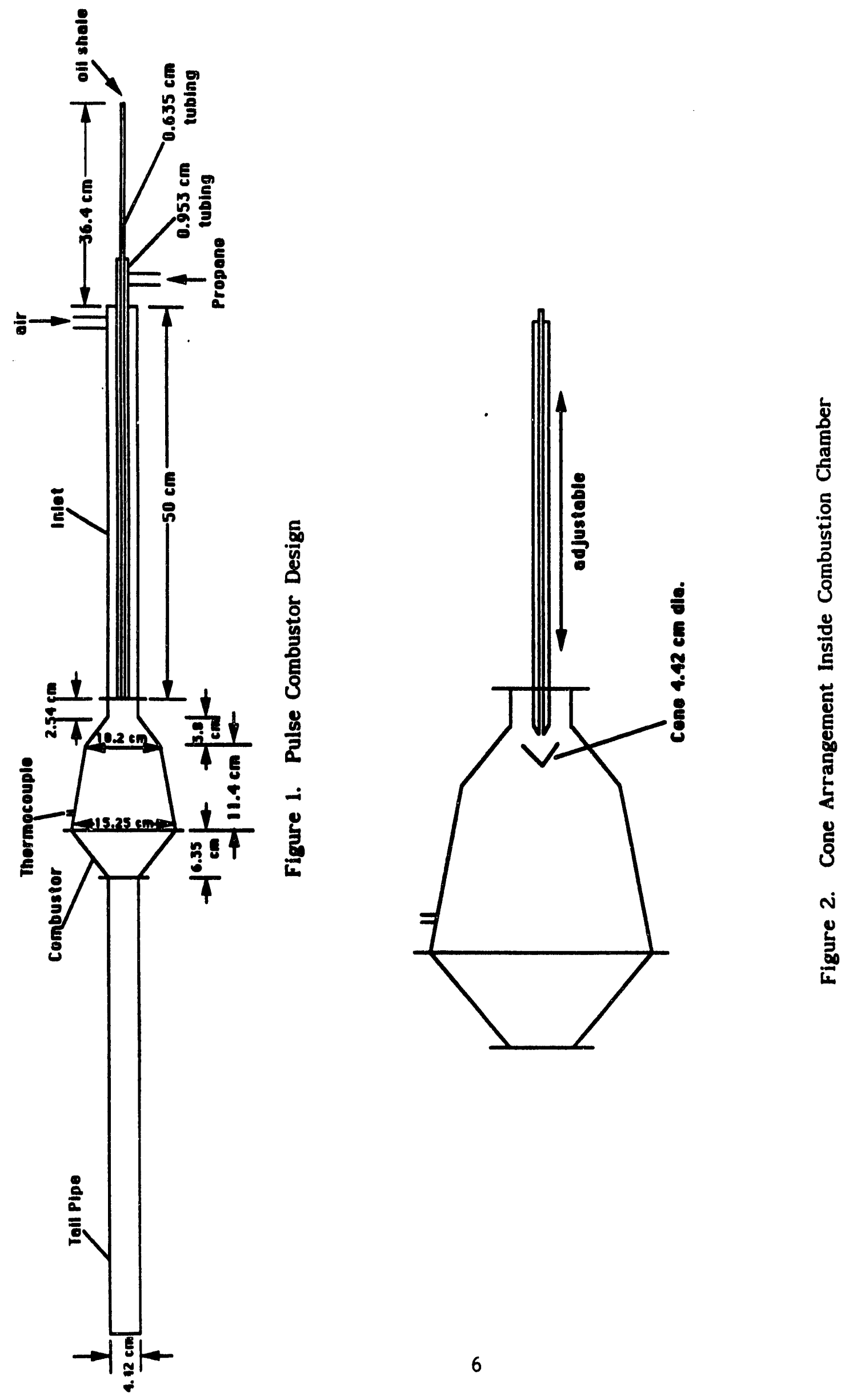
order to cause the oil shale to flow around it and thus increase the residence time in the combustion region. The pulsations were observed to be stronger with the presence of the cone. The axial position of the fuel inlet tube played a moderate role in the operation of the pulse combustor so the tube was mounted with a compression fitting to permit axial positioning to obtain the strongest amplitude pulsations. The tube was positioned for the strongest amplitude pulsation for the propane tests and fixed in this position for the remainder of the testing.

The combustion chamber was originally constructed of stainless steel and was lined with castable aluminum oxide ceramic. Tooling molds were constructed to form the 0.625 inch $(1.59 \mathrm{~cm})$ thick castable refractory inside the combustion chamber. Without the ceramic liner in place, the combustor had a volume of $3400 \mathrm{~cm}^{3}$. Several ports were cast into the liner to permit thermocouple access, pressure transducer access, optical access, spark plug ignition, and optional secondary air inlets. Figure 1 shows the shape and dimensions of the combustion shamber.

The tail pipe of the combustor was constructed of carbon steel pipe with an internal diametér of 1.75 inches $(0.69 \mathrm{~cm})$ and an external diameter of 2.0 inches $(5.08 \mathrm{~cm})$. Tail pipe lengths of two feet $(0.61 \mathrm{~m})$ and four feet $(1.22$ m) were used in this study.

A solid fuel feeder system was designed and constructed to provide as uniform a feed rate as possible. The feeder designs included a syringe pump feeder and an auger type drive combined with pneumatic conveyance to a combustor inlet port. The syringe pump feeder, designed and constructed specifically for this experiment, consisted of a two-inch $(5.08 \mathrm{~cm})$ diameter acrylic fluidized bed with a 0.18 inch $(0.46 \mathrm{~cm})$ inside diameter stainless steel tube inserted into the bed from the bottom of the bed and distributor plate. The stainless steel tube was attached to a stepper motor drive 
assembly to withdraw the tube downward through the fluidized bed at a preset rate. As the tube moved downward, the slight positive pressure within the fluidized bed caused the particles within the bed to flow into the end of the tube, thus reducing the bed height at the same rate of the tube downward velocity. A maximum flow rate of approximately $1.5 \mathrm{~kg} / \mathrm{hr}$ was possible with this syringe pump feeder. This configuration feeder worked well for large particle diameters, on the order of $50 \mu \mathrm{m}$ or larger. For particles on the order of $5 \mu \mathrm{m}$, the syringe pump feeder performed quite erratically with respect to feed rate.

The second feeder used was a Sylco Mark IX Serial 542 model that consisted of a four inch $(1.22 \mathrm{~m})$ diameter pressurized fluidized bed complete with a quarter inch $(0.635 \mathrm{~cm})$ auger drive at the bottom of the bed. The pressurized fluidized bed assisted the auger feed of the particles through pneumatic conveyance into the inlet of the combustor. A vibrator mechanism on the feeder assisted in the flow of solids from the feeder. This feeder was able to feed approximately $2.88 \mathrm{~kg} / \mathrm{hr}$ of solids to the combustor at a very stable rate.

\section{PHASE II - Characterization of the Combustor Operation}

The performance of the propane and oil shale fired pulse combustor was characterized by measuring the time history of the combustor pressure, the pulsation frequency, the average temperature of the combustion chamber wall, and the velocity of the tail pipe exiting gases. For propane tests, conditioned sampling techniques facilitated time dependent velocity measurements at the tail pipe exit plane. These parameters were measured as the fuel feed rate and tail pipe geometries were varied in an effort to characterize the operation of the combustor. The initial testing involved a brief study to investigate the effect of the presence of inert mineral 
particles in the combustor. Propane was used to fire the combustor and pulverized limestone was injected into the combustor.

Upon completion of the gaseous fuel and the inert material testing, pulverized raw oil shale was used to fuel the combustor for the parametric testing and stability mode identification. A piezoelectric pressure transducer was used to monitor the combustion chamber pressure and frequency. A K-type thermocouple was used to measure the average combustor internal wall temperature. The time dependent centerline velocity of the gases exiting the tail pipe was measured with a single channel, $15 \mathrm{~mW}$ laser Doppler anemometer (LDA) through conditioned sampling synchronized to the pressure pulse in the combustor. The LDA was operated in the forward scatter mode complete with an acousto-optic cell to alleviate directional ambiguity. Spent $5 \mu \mathrm{m}$ oil shale particles were used as seed material for the LDA measurements. Rotameters were used to measure the flow rates of the excitation air and propane. A digitizing oscilloscope was used to accurately monitor the output from the pressure transducers to determine the oscillation frequency and combustion chamber pressure amplitude.

\section{Conditioned Sampled Velocity Measurements}

Conditioned sampling or cycle resolved sampling is crucial to a comprehensive study of the nature of the oscillating flow in the tail pipe of a pulse combustor. Without the aid of this procedure, instantaneous velocity measurements of the gases in the tail pipe would be of little value. As with any cycle resolved sampling technique involving periodicity, there needs to be a reference point within the cycle with which to reference measurements. The pressure pulse in the combustion chamber was well suited for this purpose. Therefore, this transducer served a dual role, first to record the

pressure level within the combustion as a function of time and second, to 
serve as a trigger for the conditioned sampled velocity measurements at the tail pipe exit plane.

The conditioned sampled velocity measurement technique was coupled with ensemble averaging to characterize the time dependent centerline velocity at the exit plane of the pulse combustor tail pipe. The pressure transducer in the chamber triggered the LDA to acquire velocity data during one cycle at a time. As the conditioned sampled velocity measurements were taken, the time that each sample occurred with respect to the beginning of the oscillation period was also recorded. The period of pulsation was divided into twenty-five equal time intervals or time bins. The instantaneous data were then sorted in the time bins by the time from the start of the pulsation period. The data acquisition sof tware was programmed to acquire data until a user defined minimum number of velocity samples were present in each time bin. Since a few time bins exhibited some difficulty in becoming well populated during each run, a minimum of fifty velocity realizations were required for each bin after an overall minimum of 5,000 velocity samples were acquired for the entire data set. Therefore, the great majority of time bins contained a few hundred velocity samples for the ensemble averaging process. The arithmetic average was considered to be representarive of the center of each time bin. A similar technique was successfully employed by Morris [10] for conditioned sampled LDA velocity measurements in an unsteady jet flow. Figure 3 illustrates this conditioned sampled, ensemble averaging process.

The schematic diagram for the specially designed conditioned sampled trigger circuitry is shown in Figure 4. The nearly sinusoidal waveform from the pressure transducer was passed to an LM339 voltage comparator to detect the signal zero crossings. The output form the LM339 was then passed to a $7476 \mathrm{~J}-\mathrm{K}$ flip-flop which was configured as a divide-by-two device. Hence, the period of the pulses at the output of the triggering circuitry was twice 

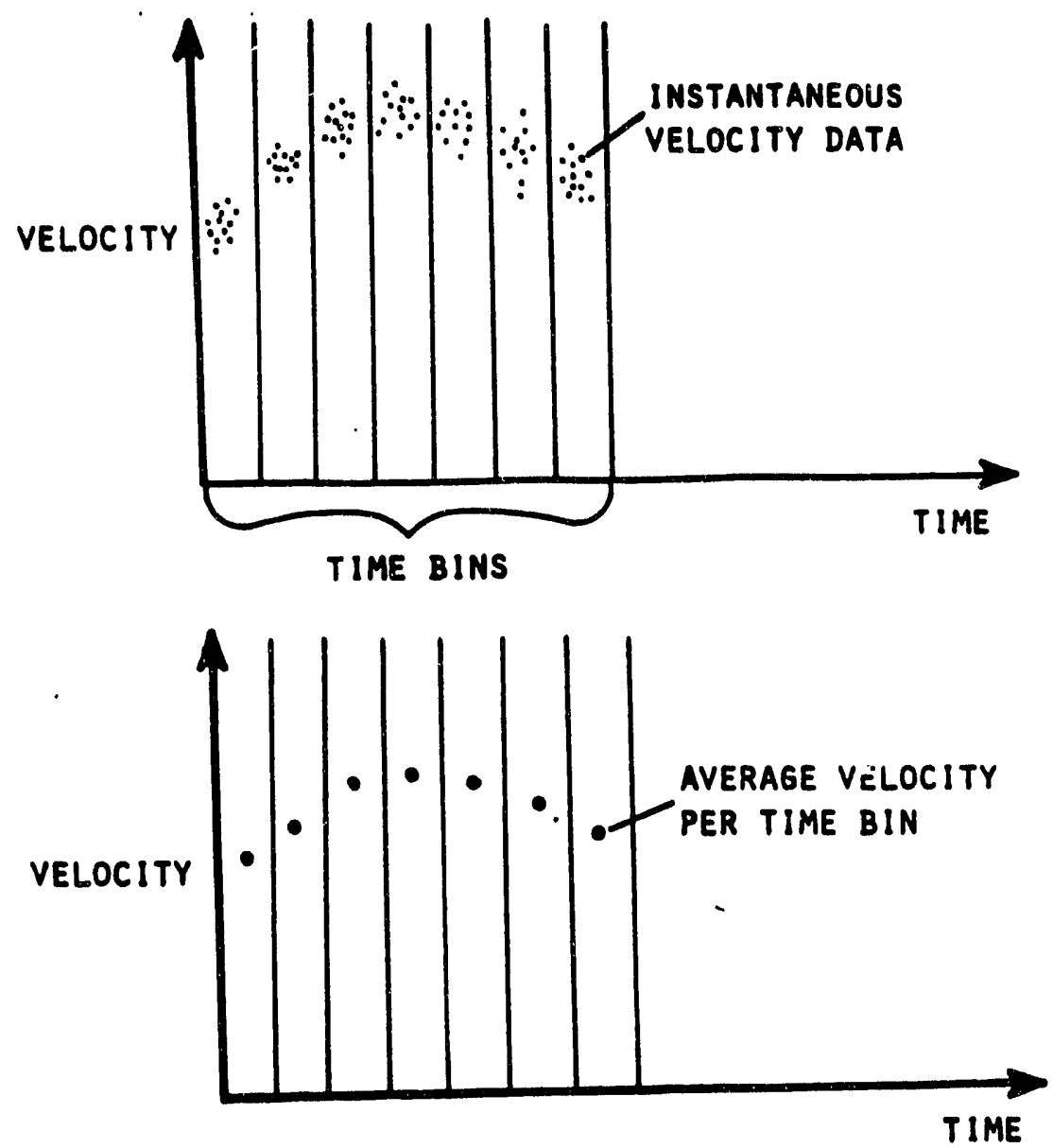

Figure 3. Conditioned Sampling with Ensemble-Averaging Process

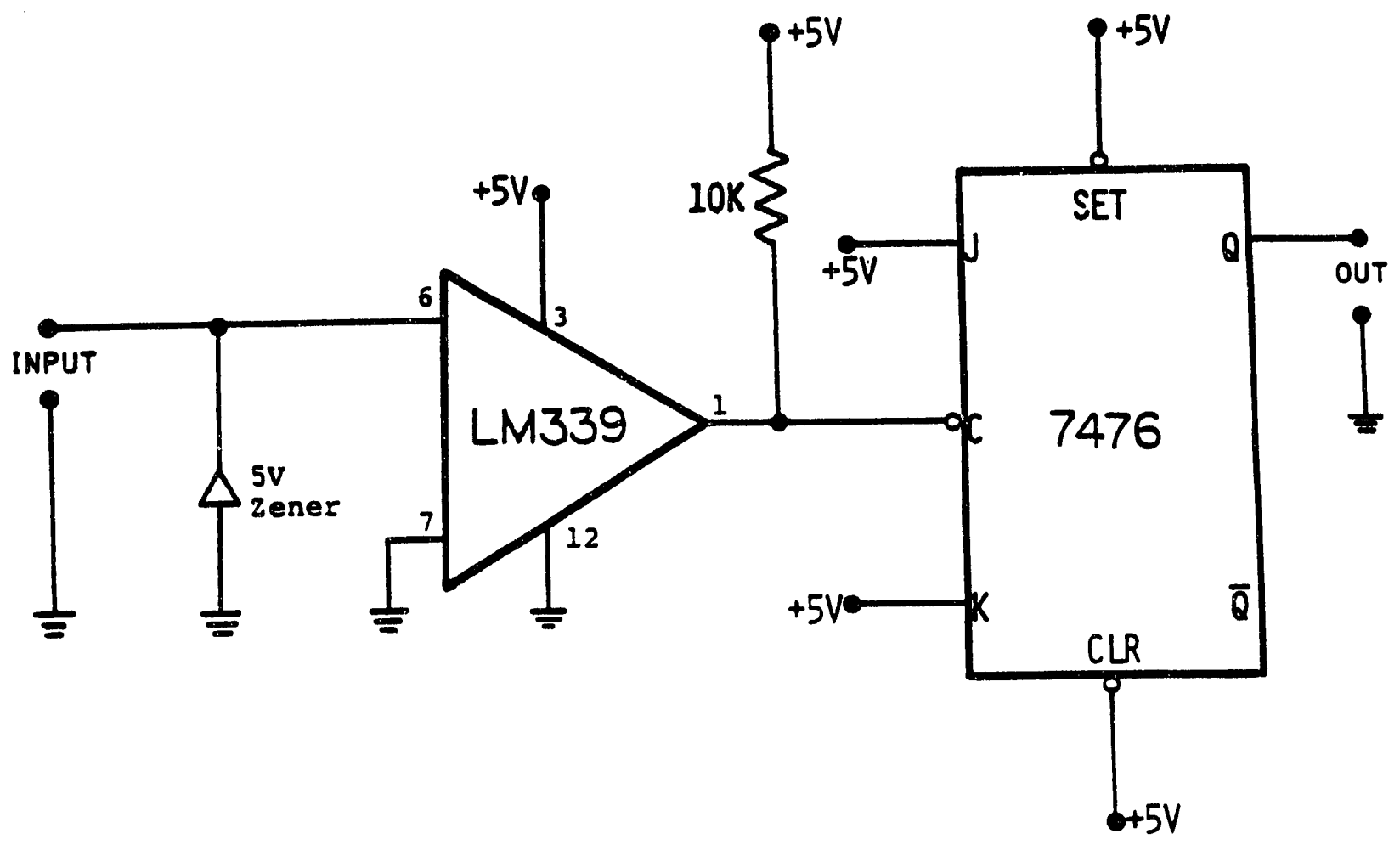

Figure 4. Schematic Diagram for the Conditioned Sampling Trigger Circuitry. 
that of the pressure transducer signal which allowed for simpler programming methods since the combustor pulsation frequency was constant. The software triggered the computer to begin accepting LDA velocity data when the output from the triggering circuitry went low and to stop accepting data when the output went high. Due to the presence of the divide-by-two device, this sequence of low and high signals describes one complete cycle of the combustor pulsation. 


\section{RESULTS}

As previously mentioned, the pulse combustor was operated in a forced mode in that the fuel and air were pressure fed into the combustor in a continuous manner. Initially, the combustor was lined with alumina refractory but this configuration proved to be problematic for other than cold start scenarios. Shortly after ignition, the temperature of the refractory lining became high enough to cause the influx of fuel and air to burn steadily without pulsations. While the refractory lining would normally be helpful for the combustion of solid fuel, it was removed to permit the combustor to pulse. The heat transfer to the atmosphere through the 20 gauge stainless steel chamber wall was sufficient to cool the walls to permit the extinction of the flame during a pulsation cycle.

The results of the experiments are presented in graphical form in various formats. The pressure histories inside the combustor were recorded by the digitizing oscilloscope and hard copies of such traces were produced. For the conditioned sampled velocity data at the exit of the combustor tail pipe, the velocity is plotted as a function of time. The results reveal the effect of varying the tail pipe length and varying the equivalence ratio. Equivalence ratios up to 1.4 were tested since an oxygen depleted exhaust stream would be desirable for oil shale retorting applications with the pulse combustor.

\section{Propane Fuel Results}

Figures $5,7,9,11$, and 13 are the pressure versus time histories of the four foot $(1.22 \mathrm{~m})$ tail pipe combustor pressure for the propane fired combustor for equivalence ratios of $0.6,0.8,1.0,1.2$, and 1.4 respectively. The combustor operated at very nearly atmospheric pressure (approximately one quarter-inch $(0.64 \mathrm{~cm})$ of water positive boost pressure) during all tests. 
Figures 6, 8, 10, 12, and 14 show the time dependent tail pipe velocities for the same respective values of equivalence ratio. For the fuel lean condition $(\phi=0.6)$ shown in Figure 5 , the combustor exhibited some minor instabilities as is indicated by the trace. The maximum pressure excursion of $1.625 \mathrm{psi}(11.2 \mathrm{kPa})$ peak-to-peak was experienced for this fuel lean condition. The pulsation frequency of $51.5 \mathrm{~Hz}$ for this condition was the lowest for all propane fired tests. As the equivalence ratio approached stoichiometric conditions, the combustor performance became more stable as is shown in Figure 9 and the stability was maintained throughout the fuel rich equivalence ratio tests (Figures 11 and 13 ).

For the tail pipe velocity plots corresponding to the propane fired combustor with the four foot $(1.22 \mathrm{~m})$ tail pipe (Figures $6,8,10,12$, and 14), the positive values are defined for the exhaust leaving the tail pipe; the negative velocities are for exhaust entering the tail pipe. Each data point on the curve indicates the center of one of the equal interval time bins as part of the conditioned sampled velocity data set. Note the high degree of repeatability of the waveforms as the equivalence ratio is varied. In all cases, the maximum exiting tail pipe velocity magnitude greatly exceeded the entering tail pipe velocity magnitude so that an overall positive average velocity resulted as the conservation of mass would dictate for a combustor with only one opening.

Figures 15, 17, 19, 21, and 23 are the pressure versus time histories of the two foot $(0.61 \mathrm{~m})$ tail pipe combustor pressure for the propane fired combustor for equivalence ratios of $0.6,0.8,1.0,1.2$, and 1.4 respectively. Figures 16, 18, 20, 22, and 24 are the time dependent tail pipe velocities for the same respective values of equivalence ratio. Due to the instability, the maximum pressure excursion of $1.82 \mathrm{psi}(12.5 \mathrm{kPa})$ peak-to-peak was experienced for $t$ - fuel lean condition. The pulsation frequency of $66.7 \mathrm{~Hz}$ 


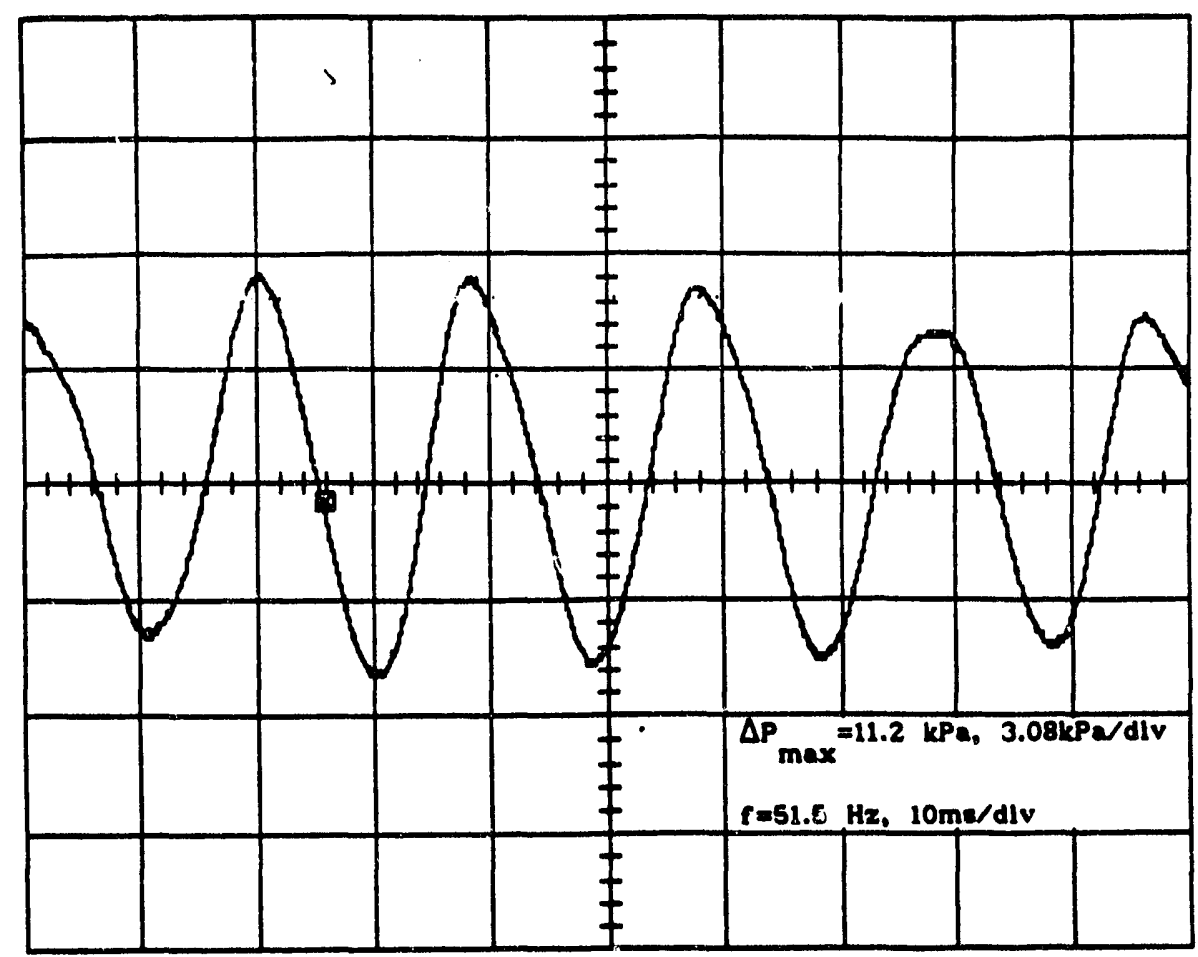

Figure 5. Pressure Excursions for the Propane Fired Pulse Combustor $(\phi=0.6$, Tail pipe $=4 \mathrm{ft}, 1.22 \mathrm{~m})$.

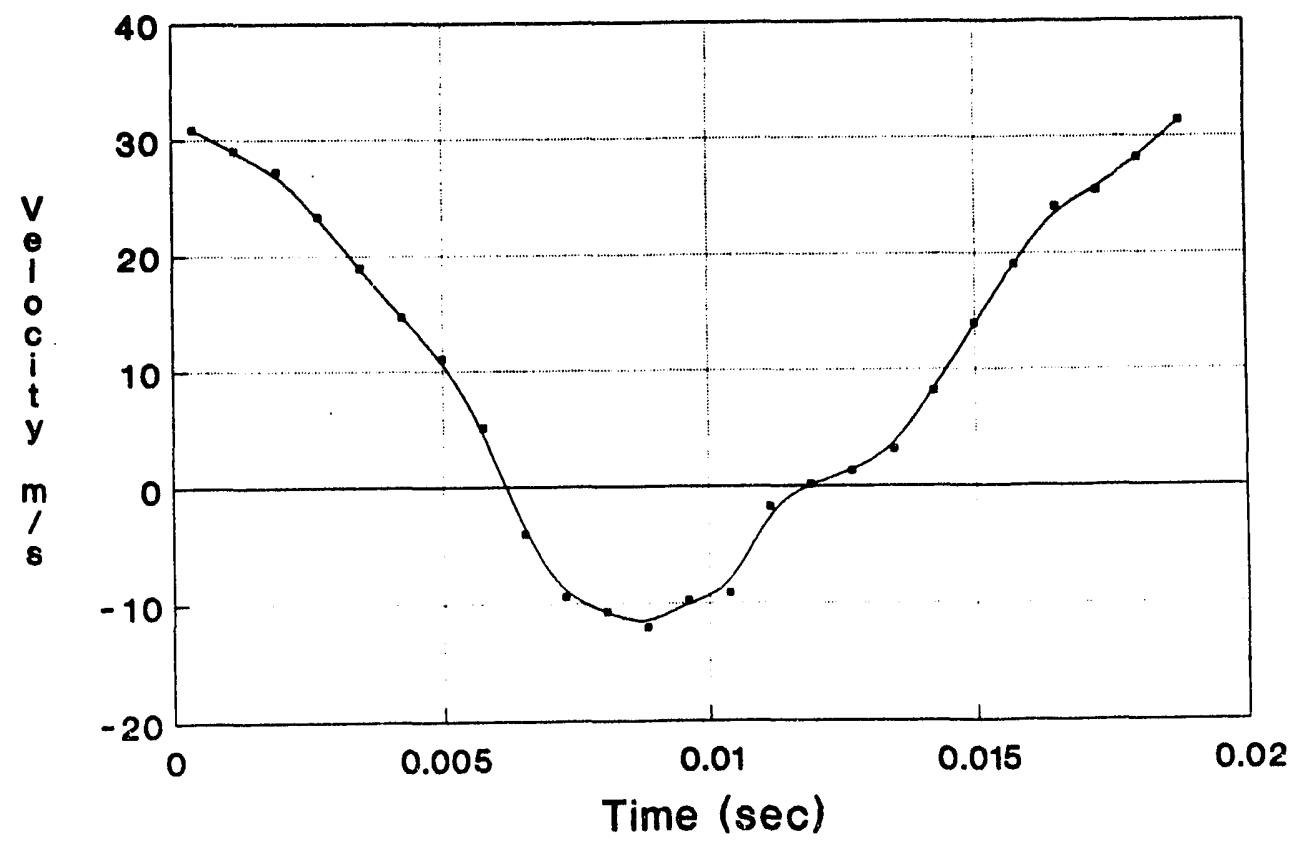

Figure 6. Time Dependent Tail Pipe Velocities for the Propane Fired Pulse Combustor $(\phi=0.6$, Tail pipe $=4 \mathrm{ft}, 1.22 \mathrm{~m})$ 


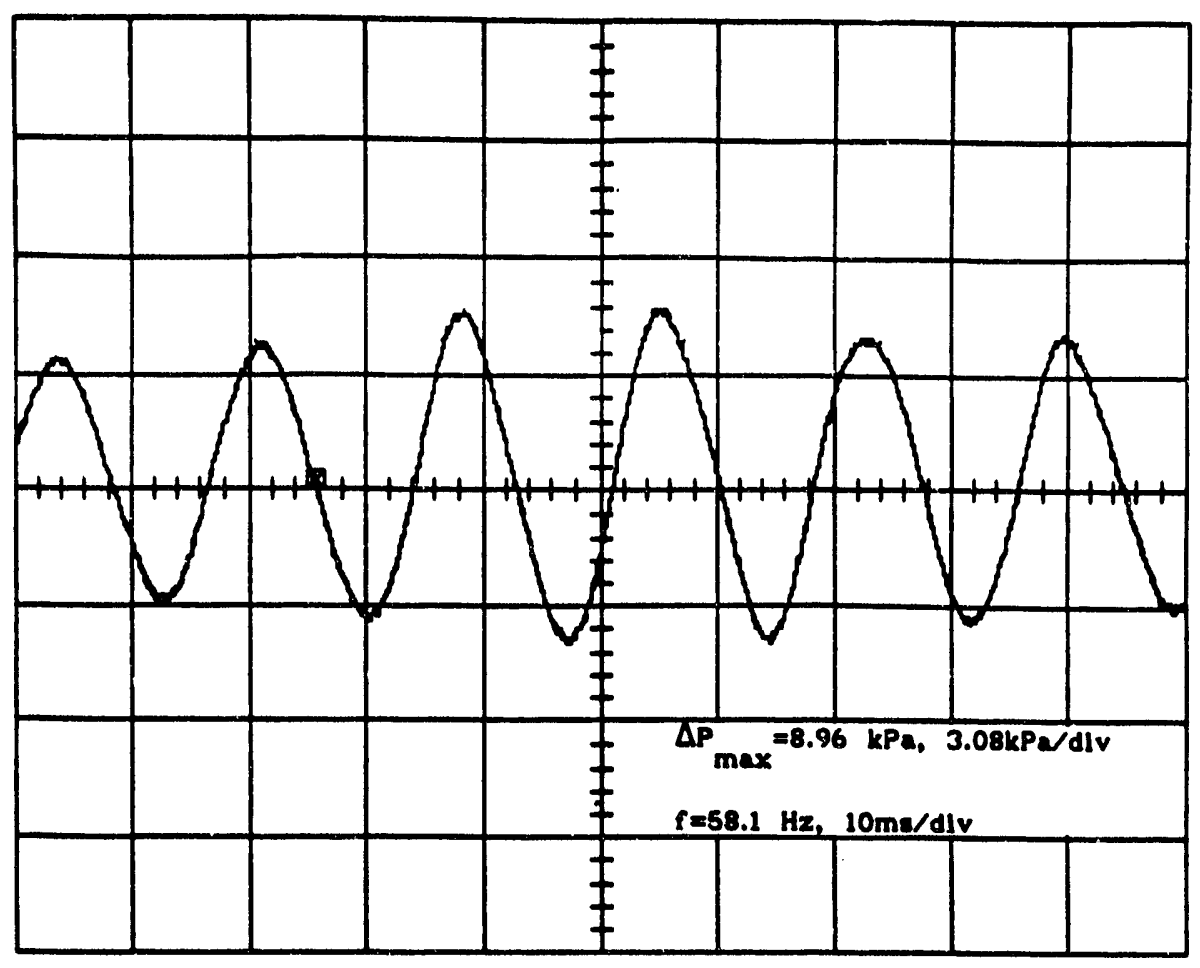

Figure 7. Pressure Excursions for the Propane Fired Pulse Combustor $(\phi=0.8$, Tail pipe $=4 \mathrm{ft}, 1.22 \mathrm{~m})$.

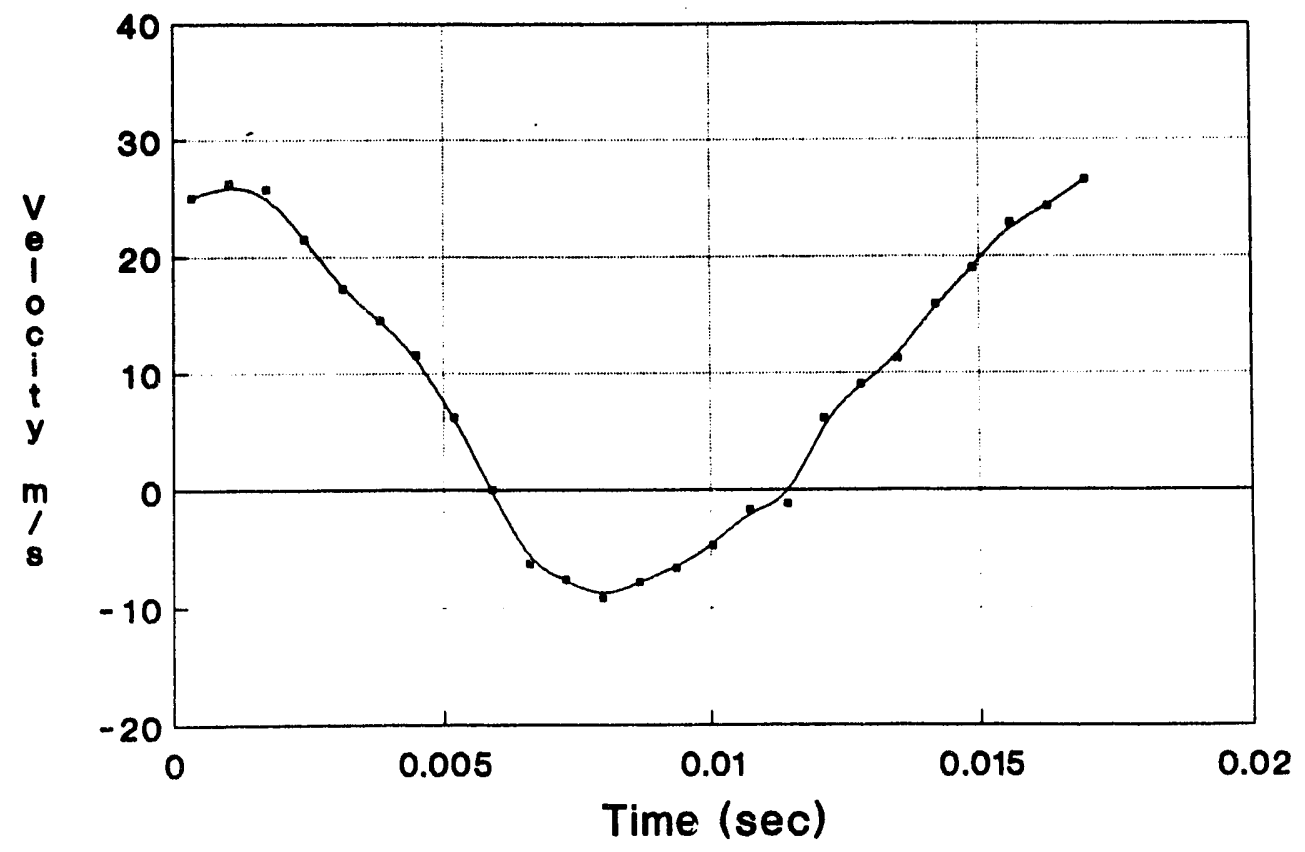

Figure 8. Time Dependent Tail Pipe Velocities for the Propane Fired Pulse Combustor $(\phi=0.8$, Tail pipe $=4 \mathrm{ft}, 1.22 \mathrm{~m})$ 


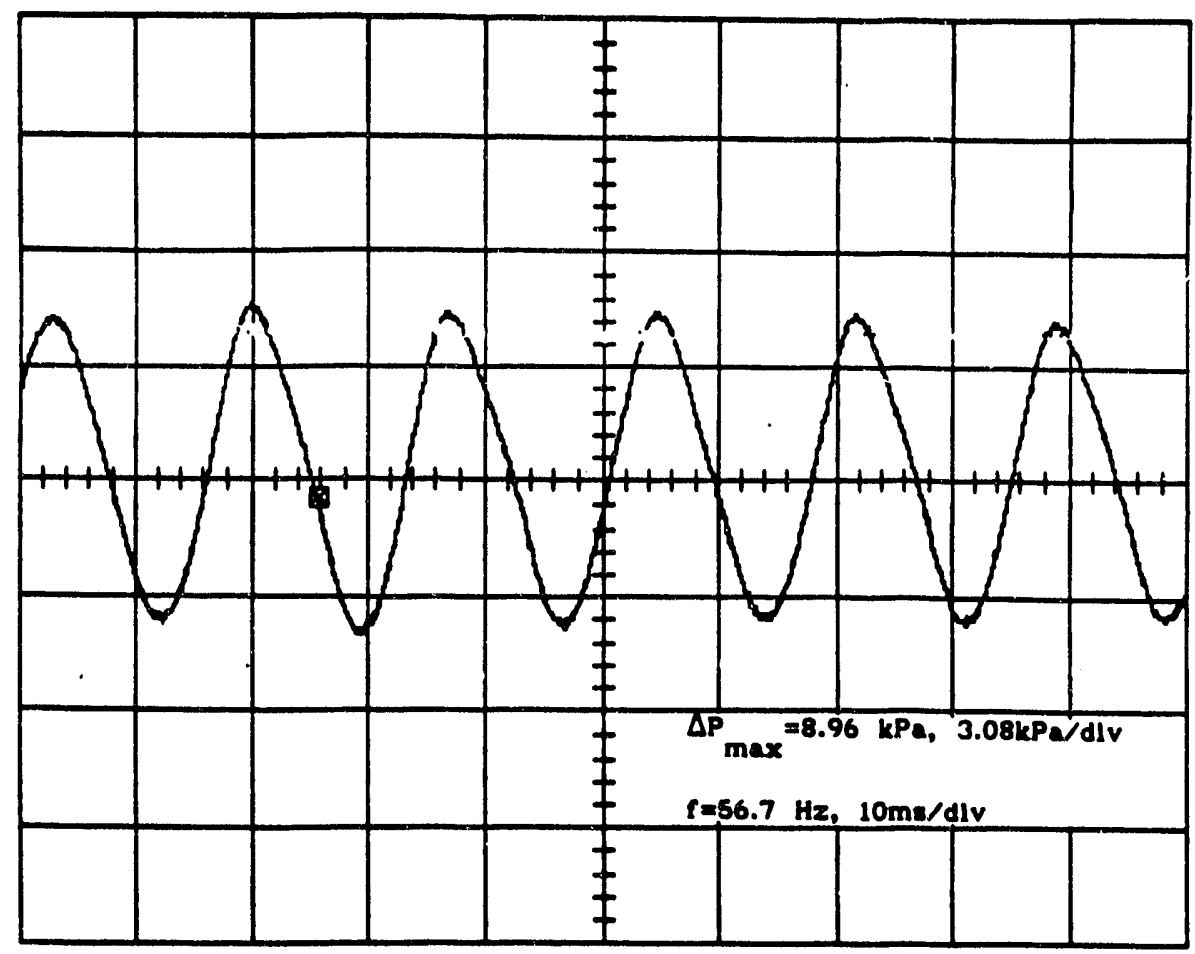

Figure 9. Pressure Excursions for the Propane Fired Pulse Combustor $(\phi=1.0$, Tail pipe $=4 \mathrm{ft}, 1.22 \mathrm{~m})$.

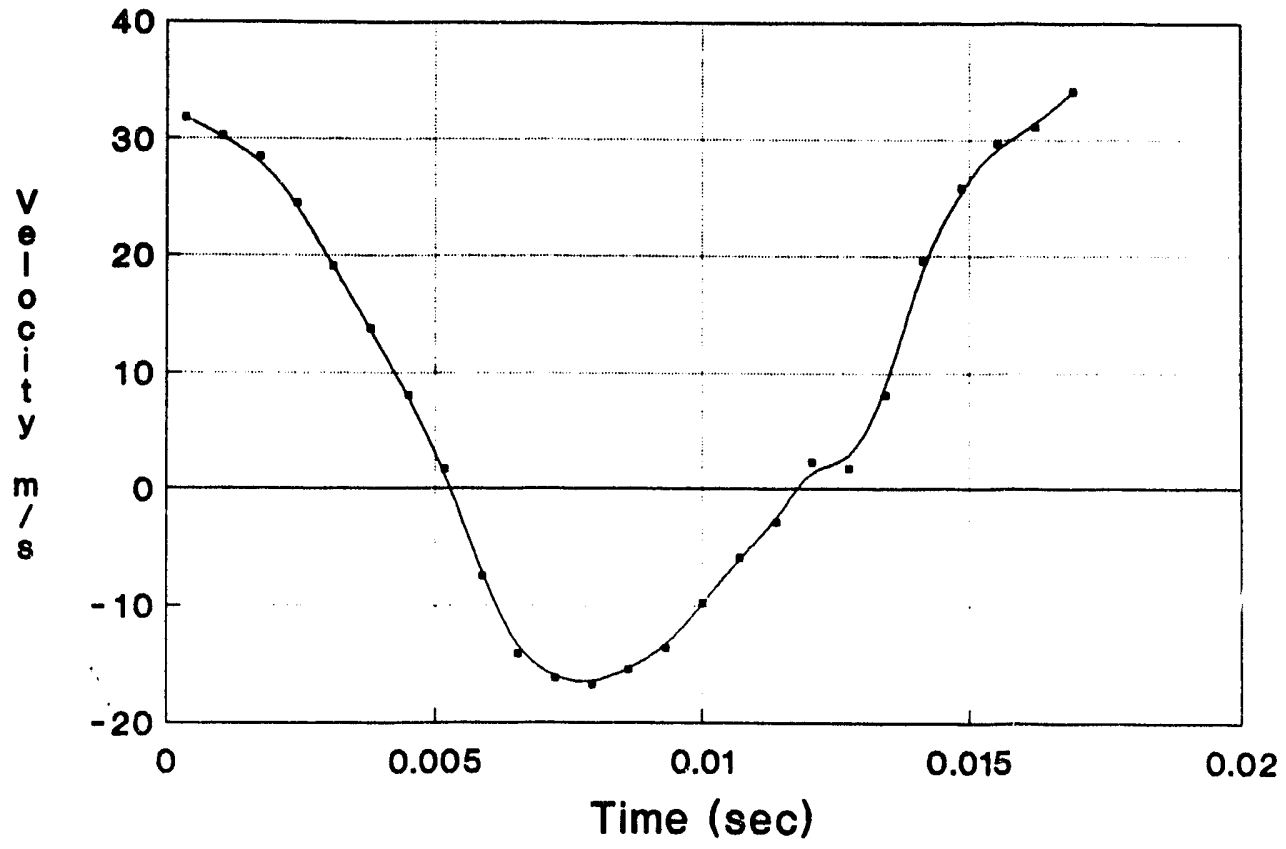

Figure 10. Time Dependent Tail Pipe Velocities for the Propane Fired Pulse Combustor $(\phi=1.0$, Tail pipe $=4 \mathrm{ft}, 1.22 \mathrm{~m})$ 


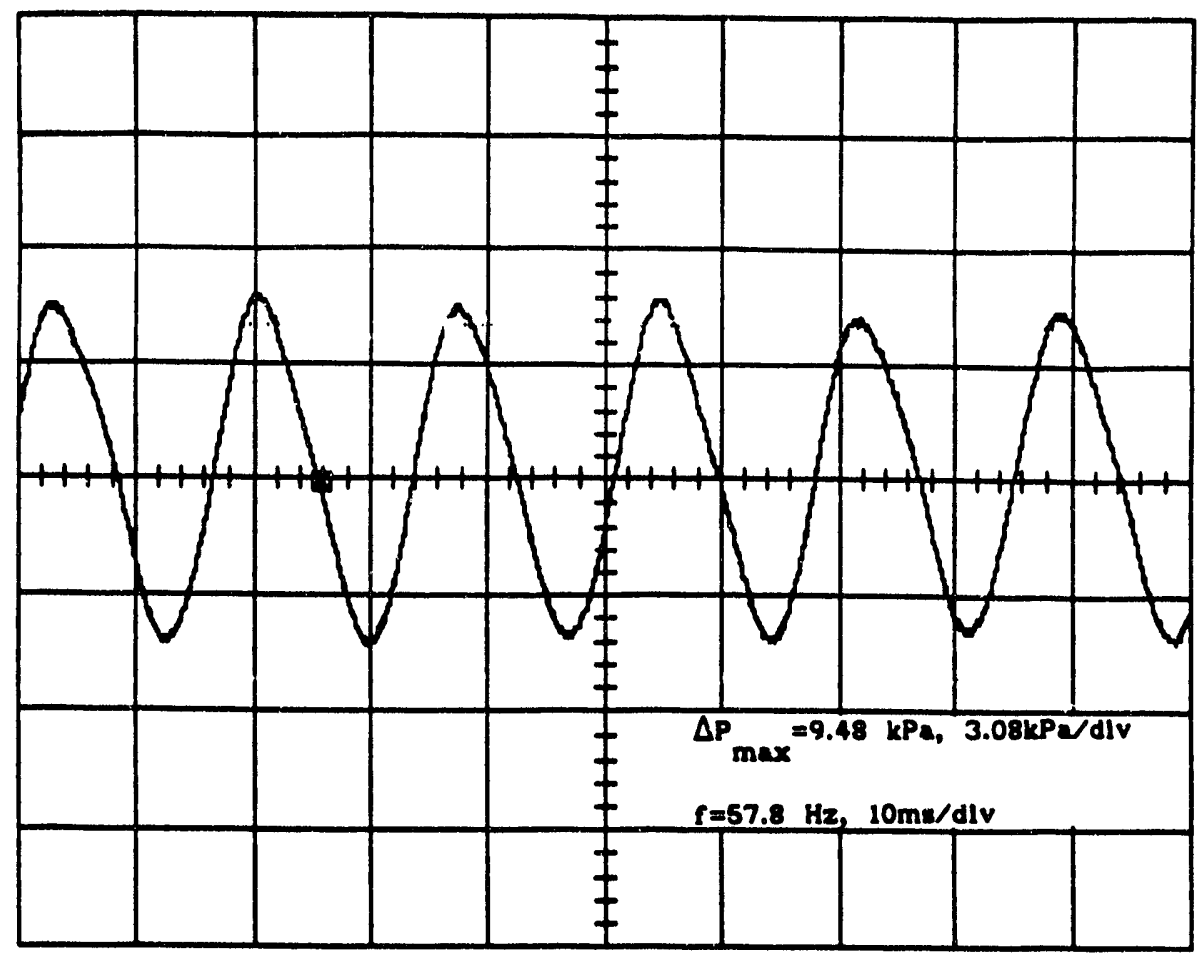

Figure 11. Pressure Excursions for the Propane Fired Pulse Combustor $(\phi=1.2$, Tail pipe $=4 \mathrm{ft}, 1.22 \mathrm{~m})$.

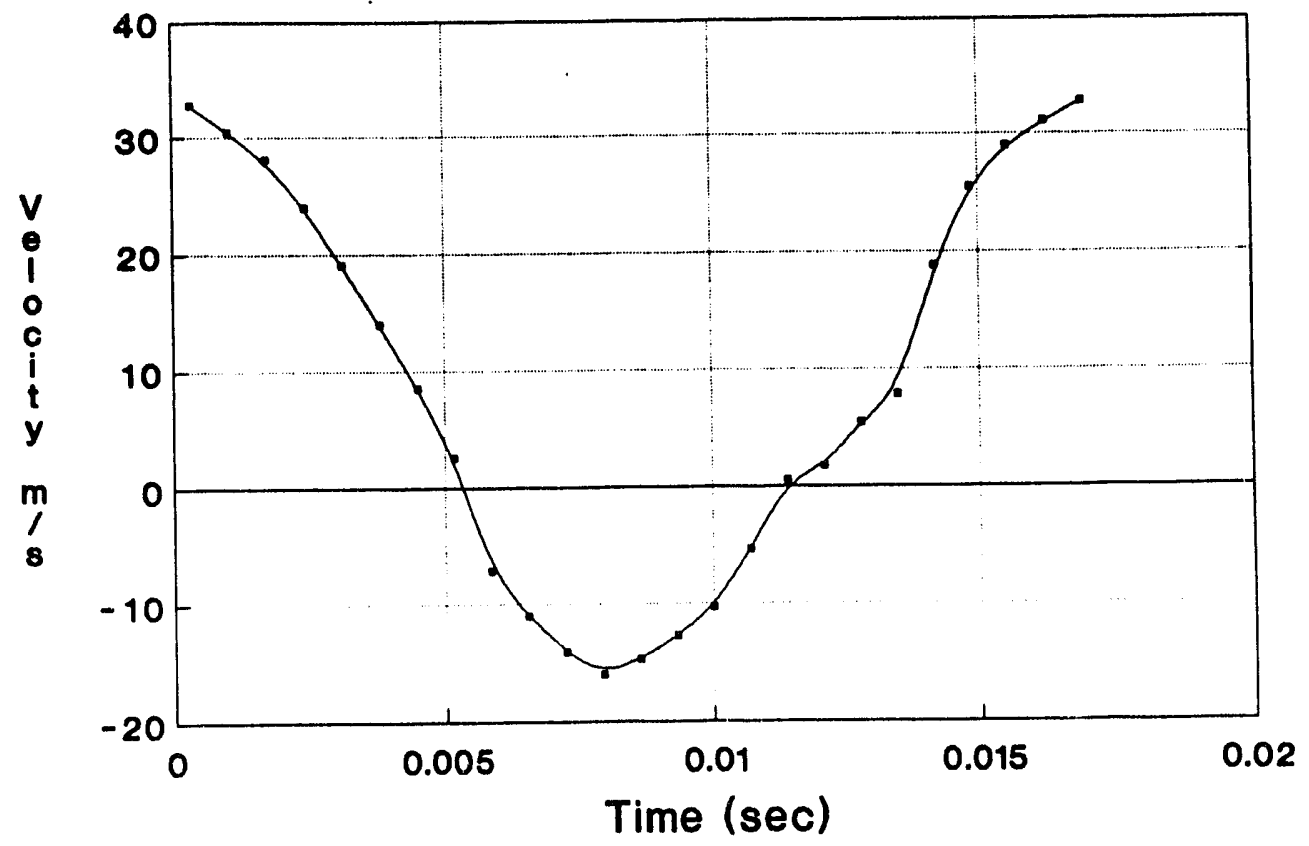

Figure 12. Time Dependent Tail Pipe Velocities for the Propane Fired Pulse Combustor $(\phi=1.2$, Tail pipe $=4 \mathrm{ft}, 1.22 \mathrm{~m})$ 


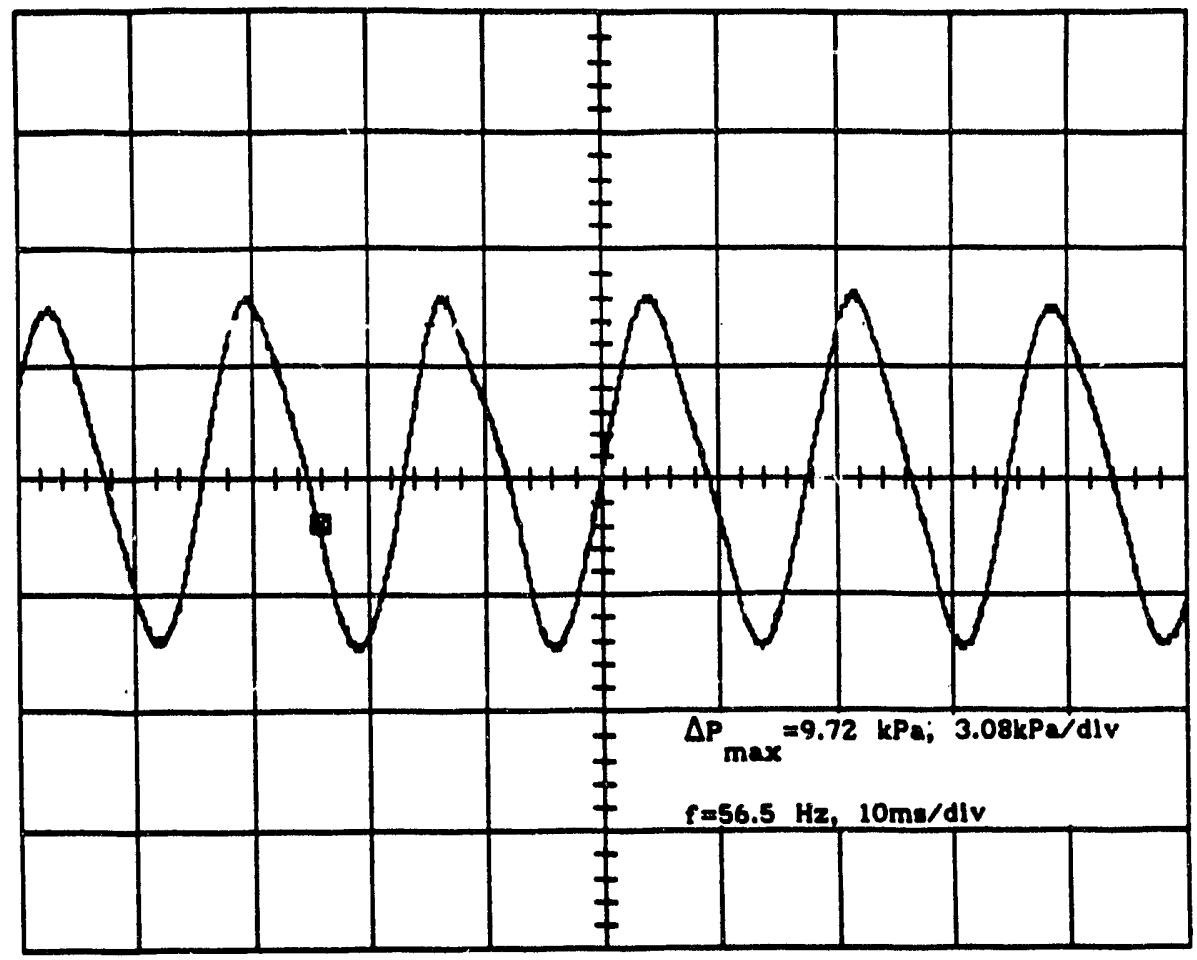

Figure 13. Pressure Excursions for the Propane Fired Pulse Combustor $(\phi=1.4$, Tail pipe $=4 \mathrm{ft}, 1.22 \mathrm{~m})$.

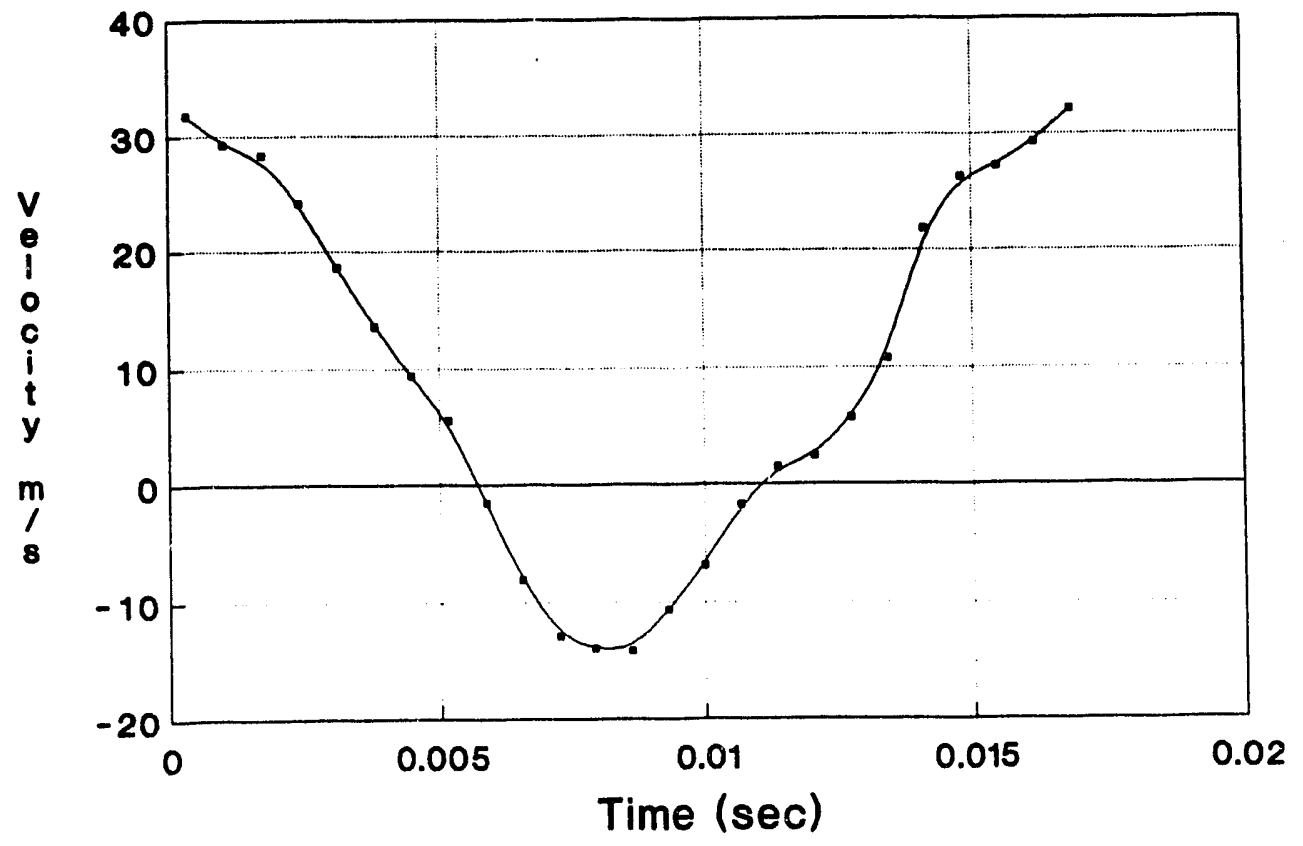

Figure 14. Time Dependent Tail Pipe Velocities for the Propane Fired Pulse Combustor $(\phi=1.4$, Tail pipe $=4 \mathrm{ft}, 1.22 \mathrm{~m})$ 


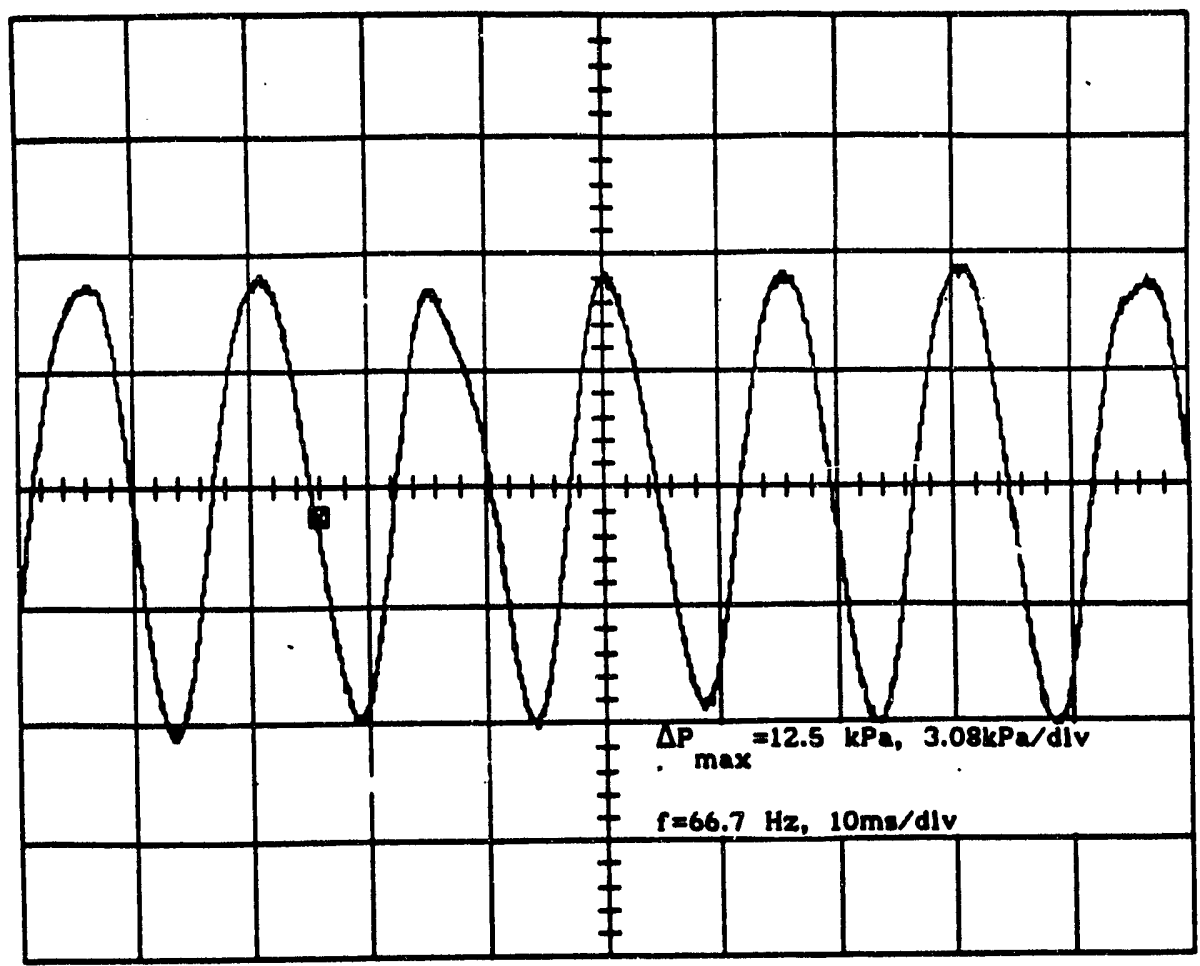

Figure 15. Pressure Excursions for the Propane Fired Pulse Combustor $(\phi=0.6$, Tail pipe $=2 \mathrm{ft}, 0.61 \mathrm{~m})$.

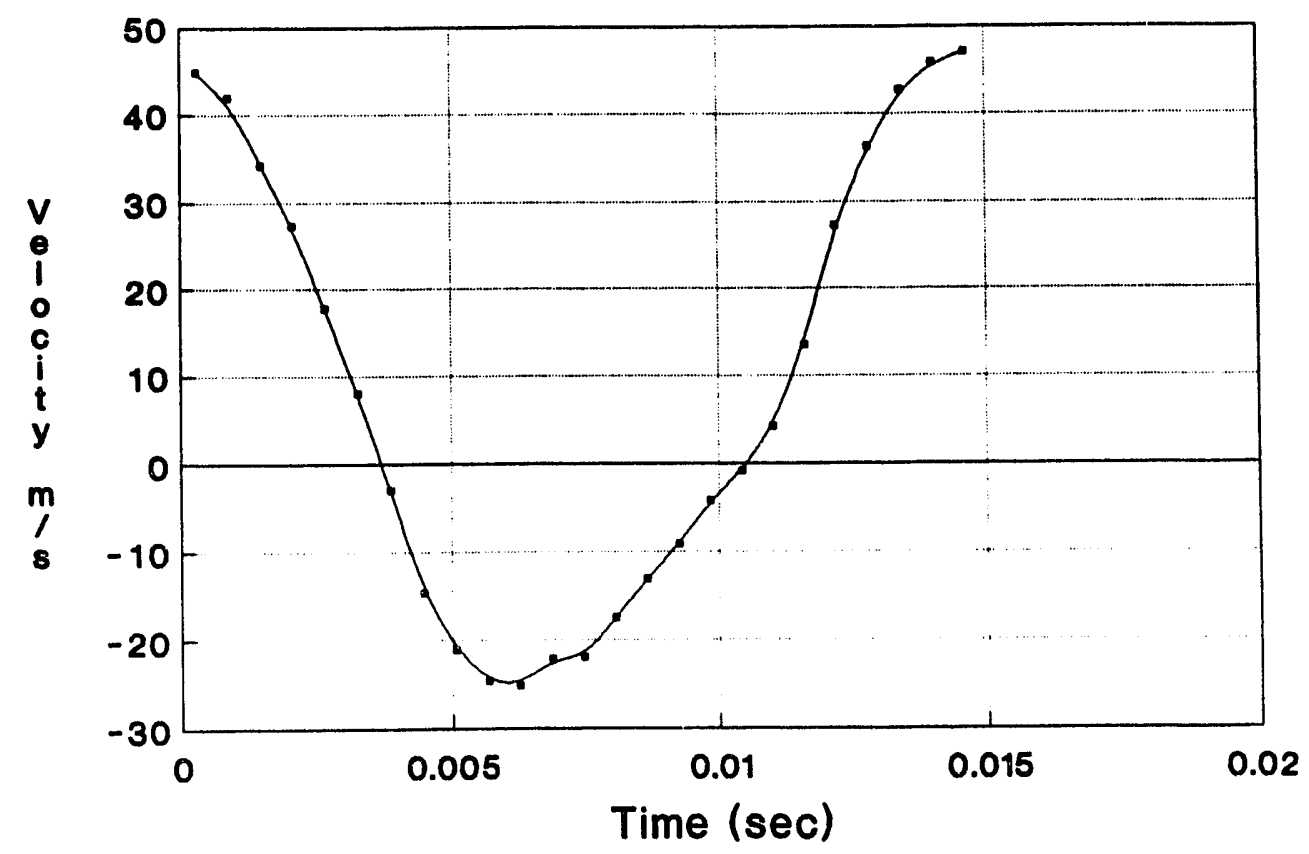

Figure 16. Time Dependent Tail Pipe Velocities for the Propane Fired Pulse Combustor $(\phi=0.6$, Tail pipe $=2 \mathrm{ft}, 0.61 \mathrm{~m})$ 


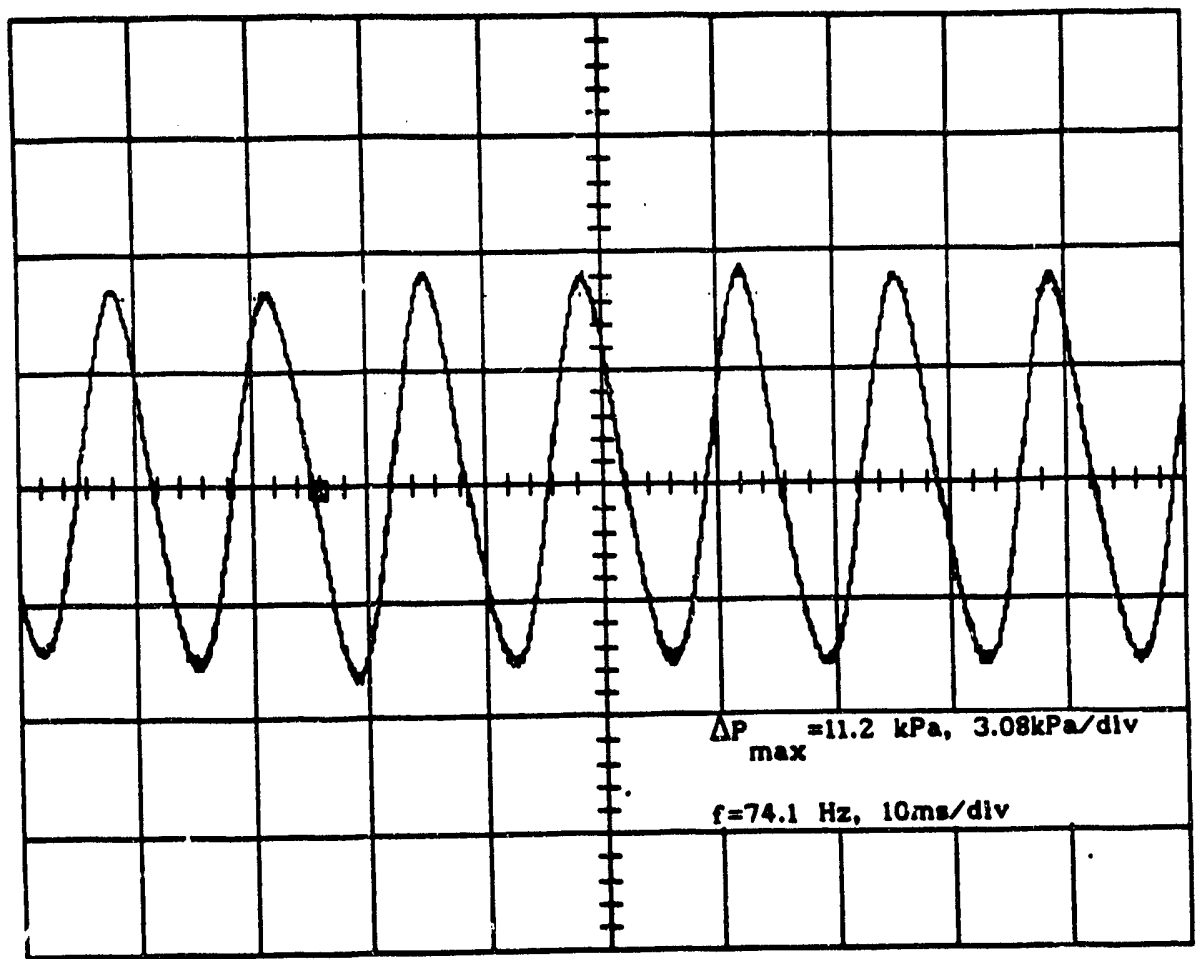

Figure 17. Pressure Excursions for the Propane Fired Pulse Combustor $(\phi=0.8$, Tail pipe $=2 \mathrm{ft}, 0.61 \mathrm{~m})$.

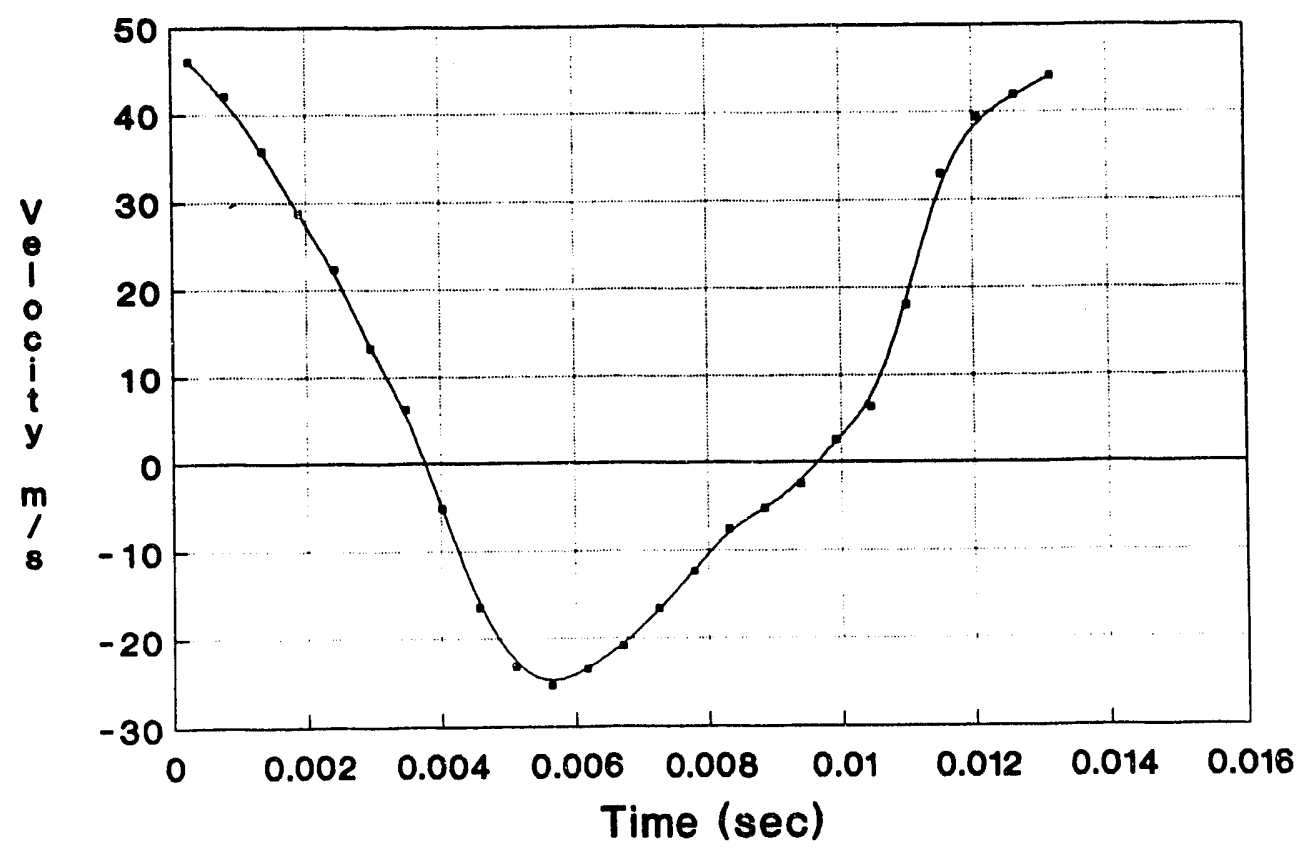

Figure 18. Time Dependent Tail Pipe Velocities for the Propane Fired Pulse Combustor $(\phi=0.8$, Tail pipe $=2 \mathrm{ft}, 0.61 \mathrm{~m})$ 


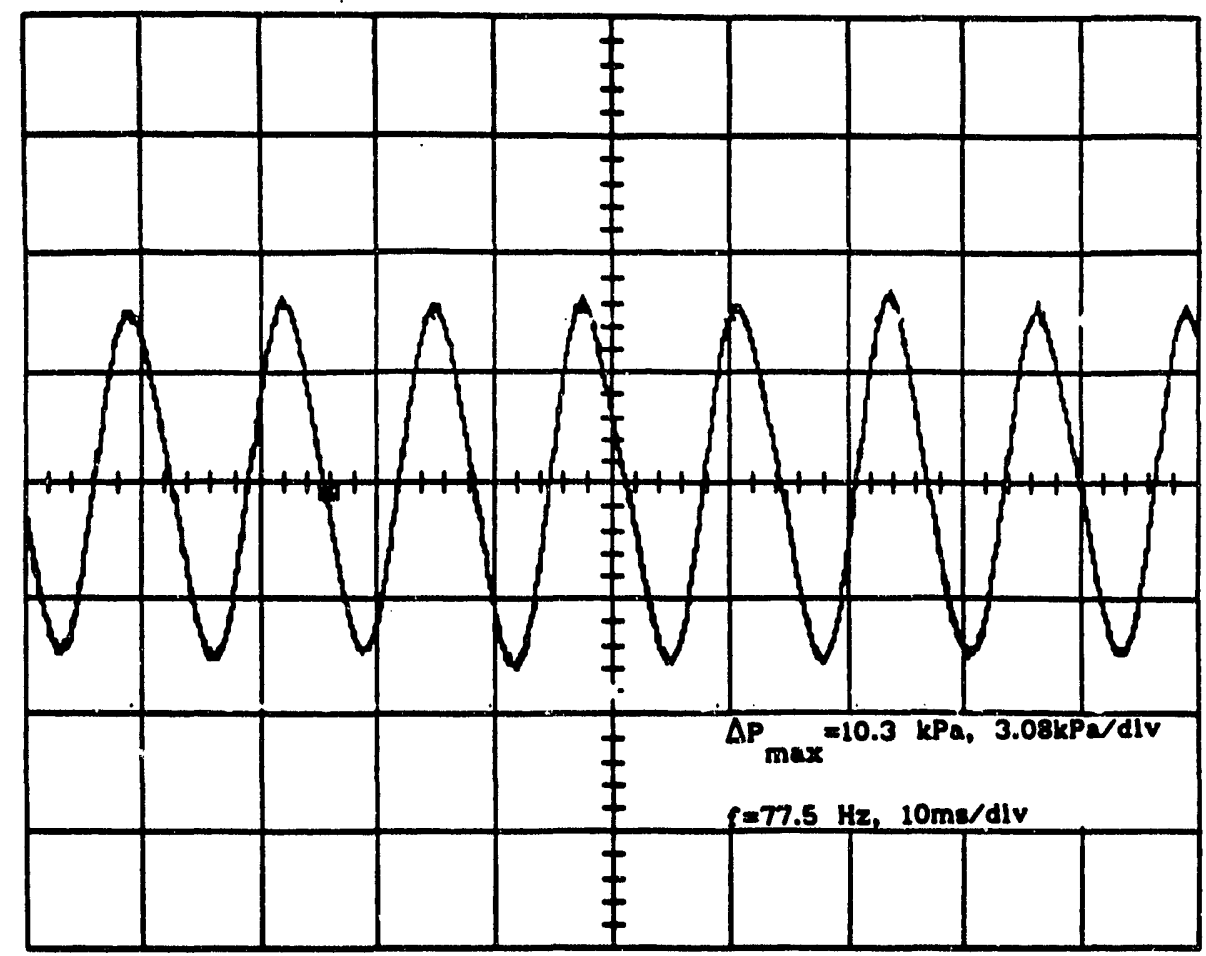

Figure 19. Pressure Excursions for the Propane Fired Pulse Combustor $(\phi=1.0$, Tail nipe $=2 \mathrm{ft}, 0.61 \mathrm{~m})$.

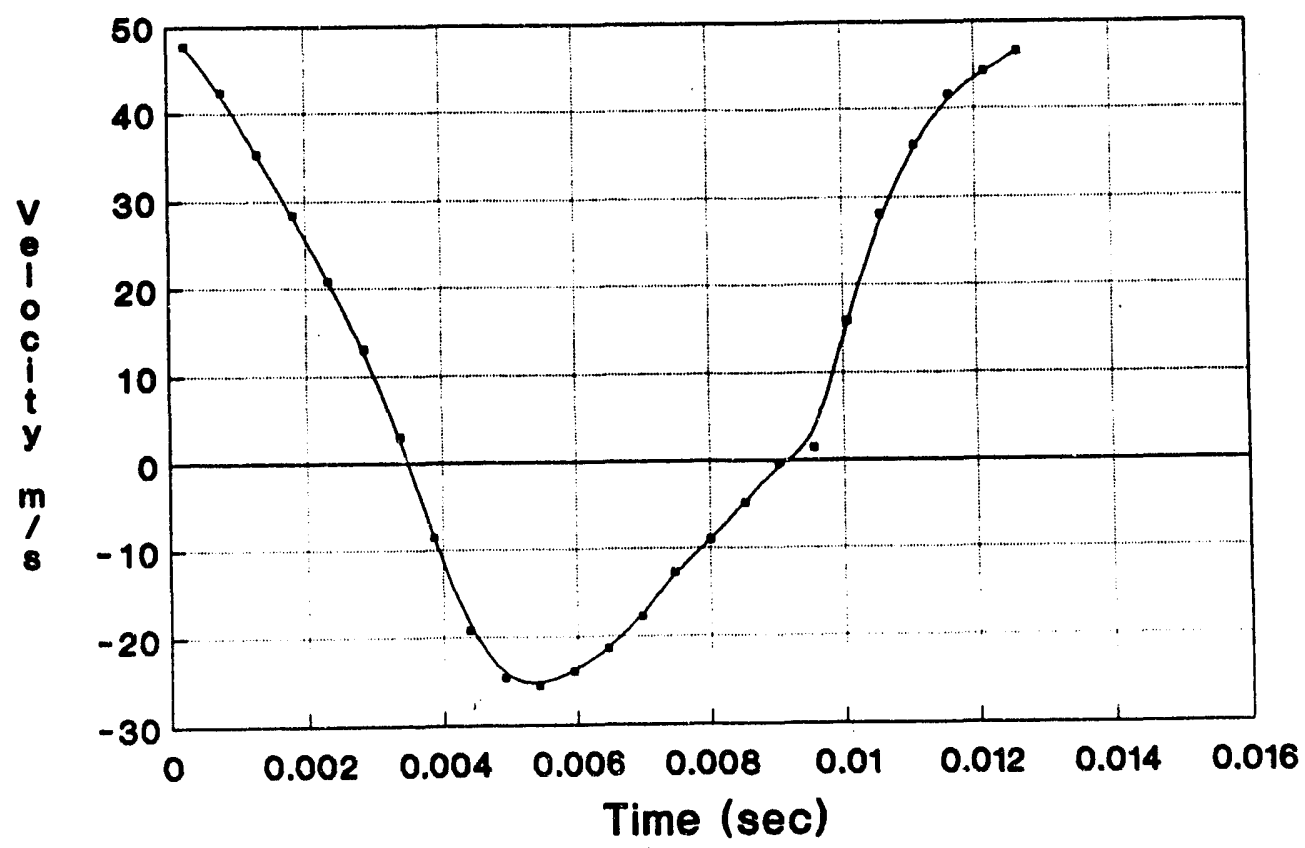

Figure 20. Time Dependent Tail Pipe Velocities for the Propane Fired Pisise Combustor $(\phi=1.0$, Tail pipe $=2 \mathrm{ft}, 0.61 \mathrm{~m})$ 


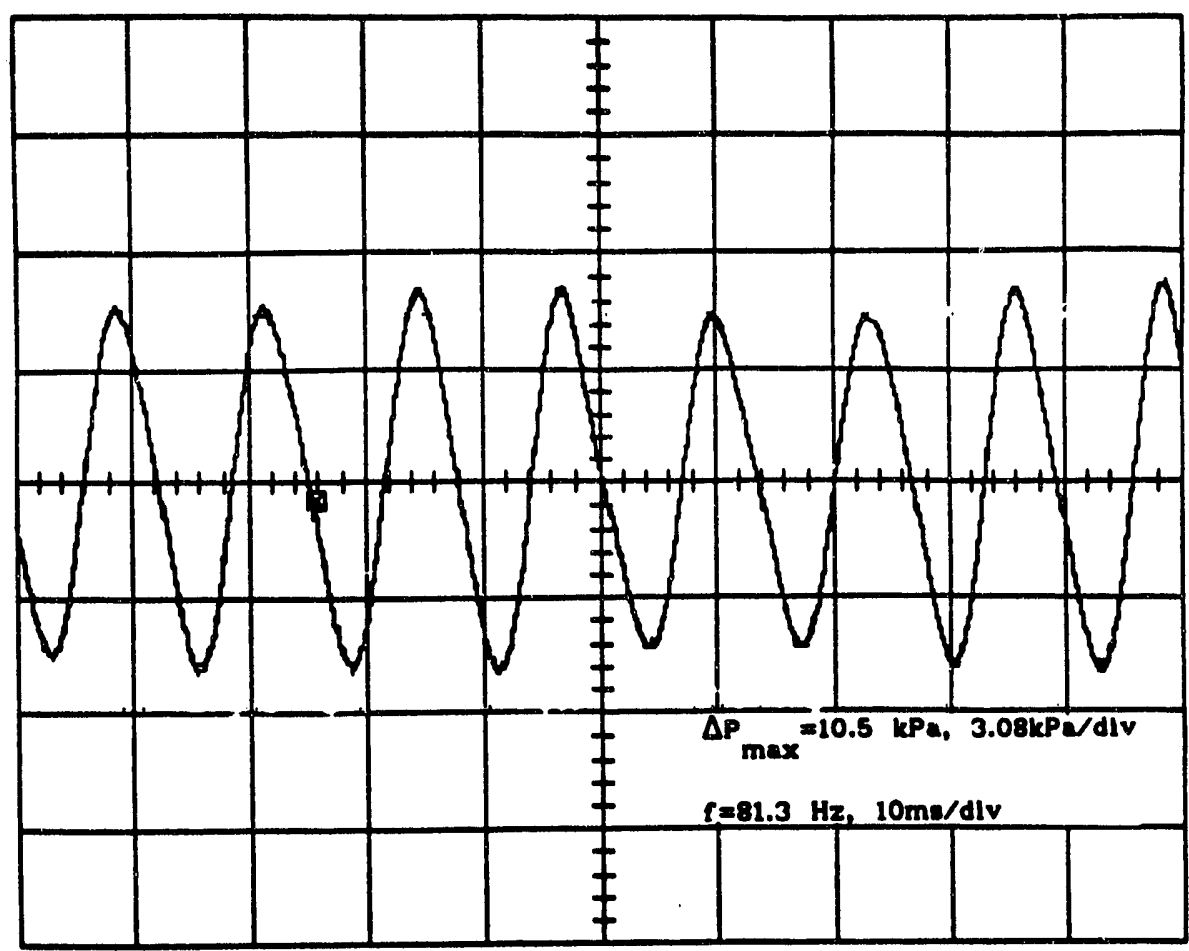

Figure 21. Pressure Excursions for the Propane Fired Pulse Combustor $(\phi=1.2$, Tail pipe $=2 \mathrm{ft}, 0.61 \mathrm{~m})$.

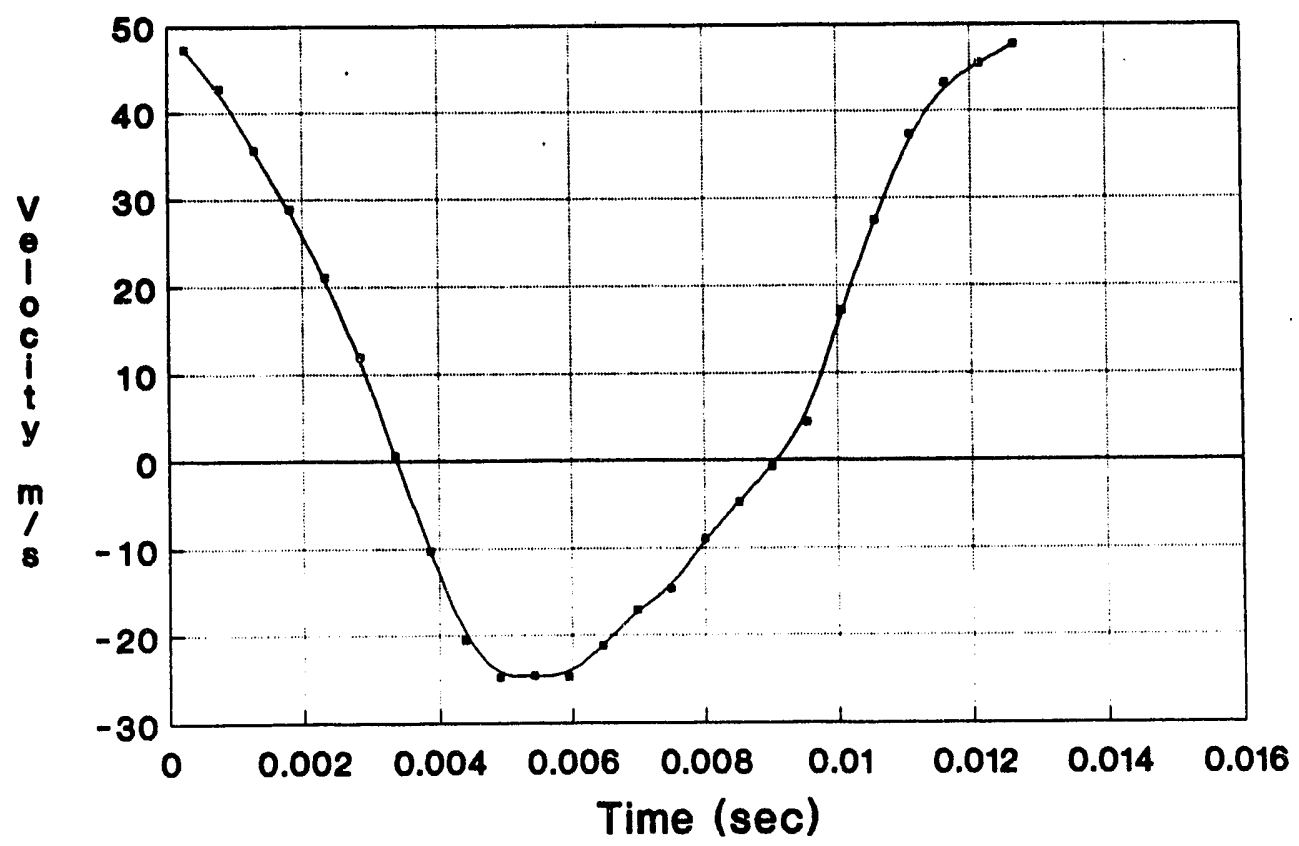

Figure 22. Time Dependent Tail Pipe Velocities for the Propane Fired Pulse Combustor $(\phi=1.2$, Tail pipe $=2 \mathrm{ft}, 0.61 \mathrm{~m})$ 


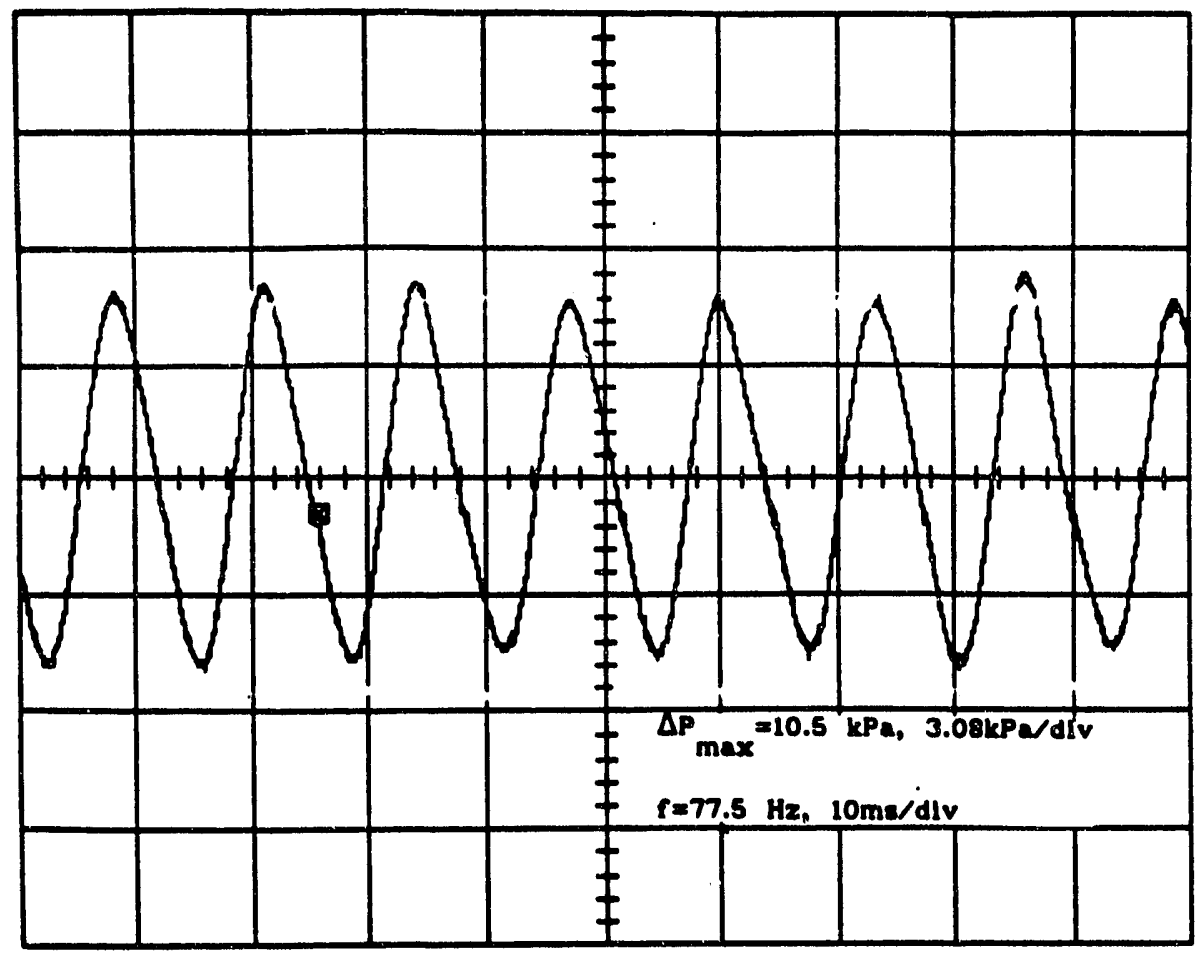

Figure 23. Pressure Excursions for the Propane Fired Pulse Combustor $(\phi=1.4$, Tail pipe $=2 \mathrm{ft}, 0.61 \mathrm{~m})$.

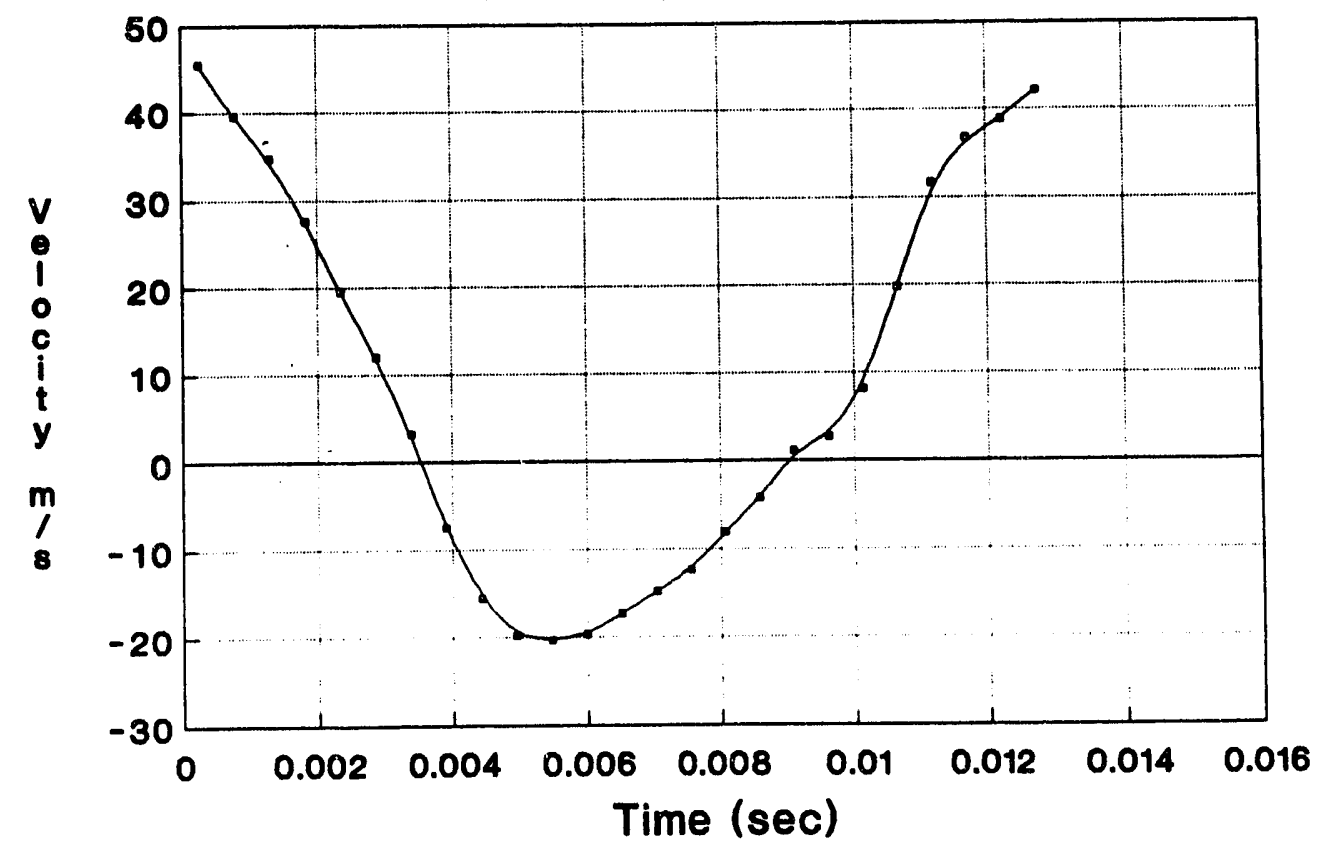

Figure 24. Time Dependent Tail Pipe Velocities for the Propane Fired Pulse Combustor $(\phi=1.4$, Tail pipe $=2 \mathrm{ft}, 0.61 \mathrm{~m})$ 
for this condition was the lowest for all tests using the two foot tail pipe. With the two foot $(0.61 \mathrm{~m})$ tail pipe in place, the combustor performance was stable for all ranges of equivalence ratios tested, a characteristic not followed for the longer tail pipe combustor. For the velocity plots corresponding to the propane fired combustor with the two foot tail pipe (Figures 16, 18, 20, 22, and 24), the positive values are defined for the exhaust leaving the tail pipe; the negative velocities are for exhaust entering the tail pipe. As for the four foot tail pipe length, a high degree of repeatability of the waveforms exists as the equivalence ratio is varied. In all cases, the maximum exiting tail pipe velocity magnitude greatly exceeded the entering tail pipe velocity magnitude so that an overall positive average velocity resulted.

Figure 25 and 26 show the effect of increasing the equivalence ratio on the maximum peak-to-peak pressure excursion and the pulsation frequency respectively. For lower pressure excursions higher frequencies occurred as expected for each tail pipe length. The combustor with the four foot 11.22 m) tail pipe experienced reduced pressure excursions and frequencies compared to the combustor with the two foot tail pipe at comparable equivalence ratios. The reduction in pressure excursions may be attributed to increased heat transfer and viscous losses in the longer tail pipe, while the reduction in pulsation frequency was due to the increase in resonance frequency of the longer tail pipe combustor.

\section{Propane and Limestone Fuel}

The effect of injecting pulverized limestone $(5 \mu \mathrm{m}$ diameter $)$ into the pulse combustor fueled by propane was investigated. For limestone injected at the maximum rate of $2.88 \mathrm{~kg} / \mathrm{hr}$, only a maximum $10 \%$ decrease in pressure amplitude was experienced with a negligible change in frequency for the range 


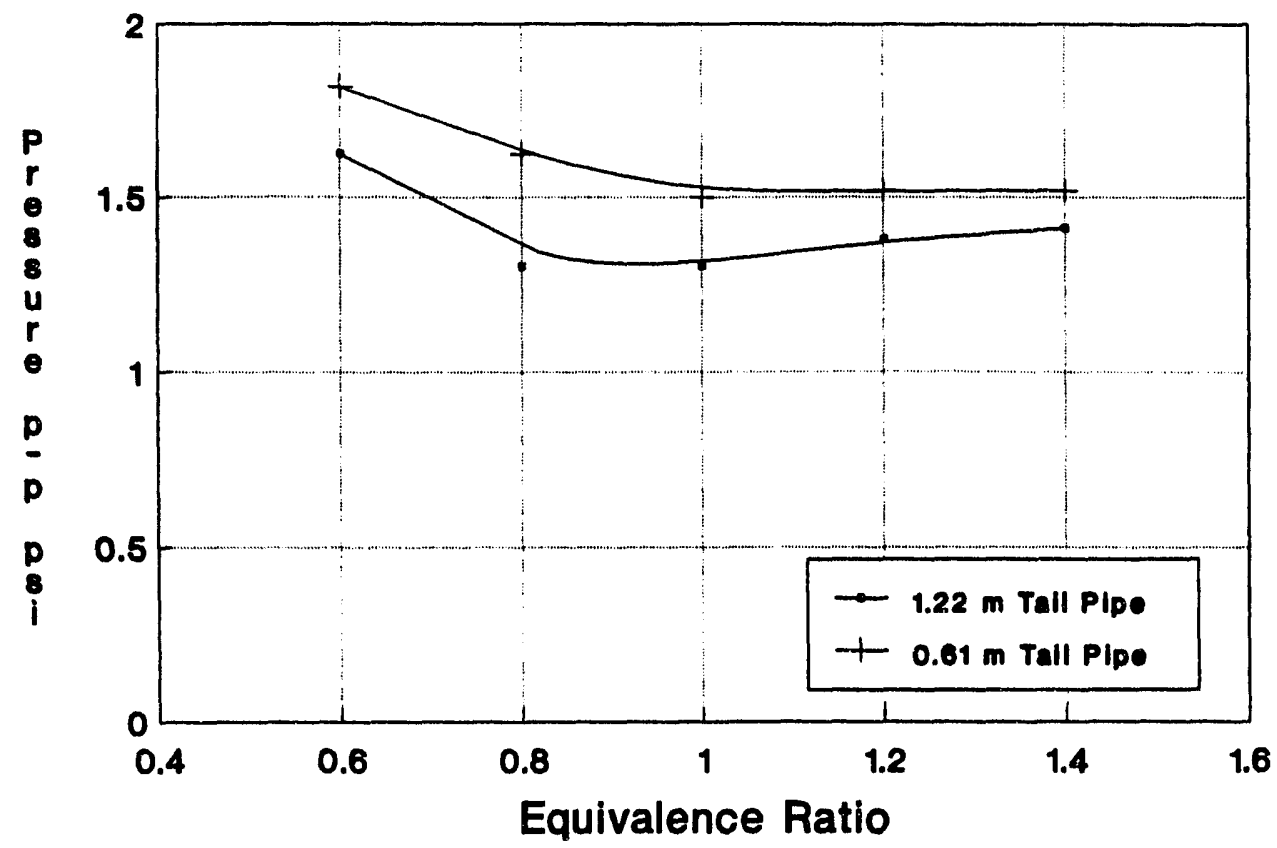

Figure 25. Effect of Equivalence Ratio on Maximum Pressure Excursions for the Propane Fired Pulse Combustor (Tail pipe $=4 \mathrm{ft}, 1.22 \mathrm{~m}$ ).

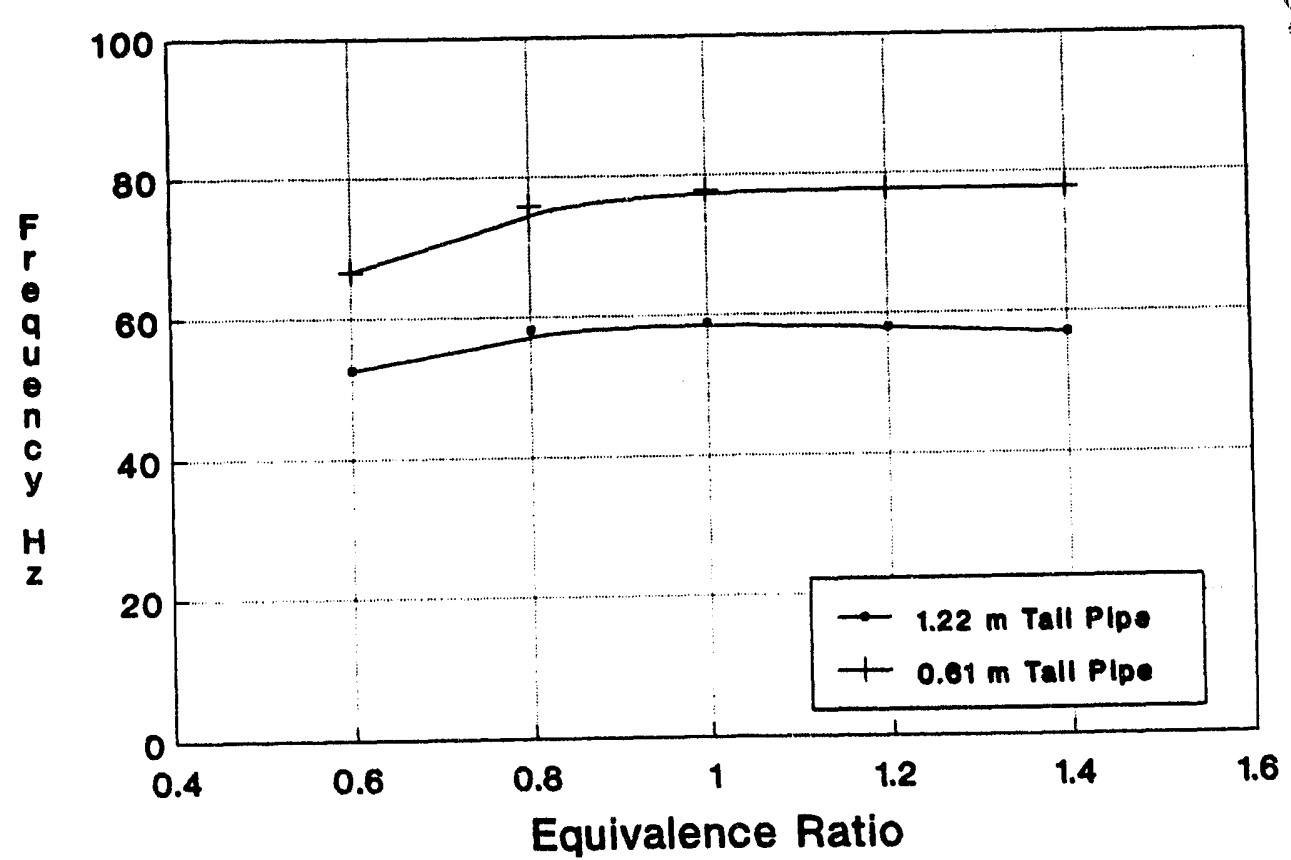

Figure 26. Effect of Equivalence Ratio on Pulsation Frequency for the Propane Fired Pulse Combustor (Tail pipe $=4 \mathrm{ft}, 1.22 \mathrm{~m}$ ). 
of equivalence ratios tested. The propane flow rates ranged up to 11.1 liters/minute.

Propane and Oil Shale Fuel

Several combustor tests were performed by co-firing the combustor with both propane and pulverized oil shale. Both $5 \mu \mathrm{m}$ and $50 \mu \mathrm{m}$ oil shale batches were tested. Research with the $50 \mu \mathrm{m}$ batch was quickly abandoned due to the accumulation of particles in the horizontally mounted combustor which caused the combustor to enter into a steady flame mode. Apparently this accumulation simulated a refractory lining in the combustor operating in the thermal mode.

In general, upon injection of the $5 \mu \mathrm{m}$ oil shale with propane, the internal wall temperature of the combustor increased approximately $100^{\circ} \mathrm{C}$ indicating energy release from the shale. Ash tracer analysis on the spent oil shale revealed up to $80 \%$ of the hydrocarbon material had combusted.

The test matrix for the combined fuel testing was designed with the assumption that the gas phase propane reactions were much more rapid than the solid phase reactions for the oil shale. The equivalence ratio was determined based on the amount of air left to react with the oil shale after the propane achieved complete combustion. Figure 27 displays the effect of varying the equivalence ratio on the pulsation frequency which is a minimum for stoichiometric conditions. Figure 28 indicates that the maximum pressure excursion occurred at stoichiometric conditions, an opposite trend compared with frequency. Figure 29 shows the effect of varying the equivalence ratio on the internal wall temperature. Note that the wall temperature increased with increasing equivalence ratio until stoichiometric conditions were experienced where it then became less sensitive. 


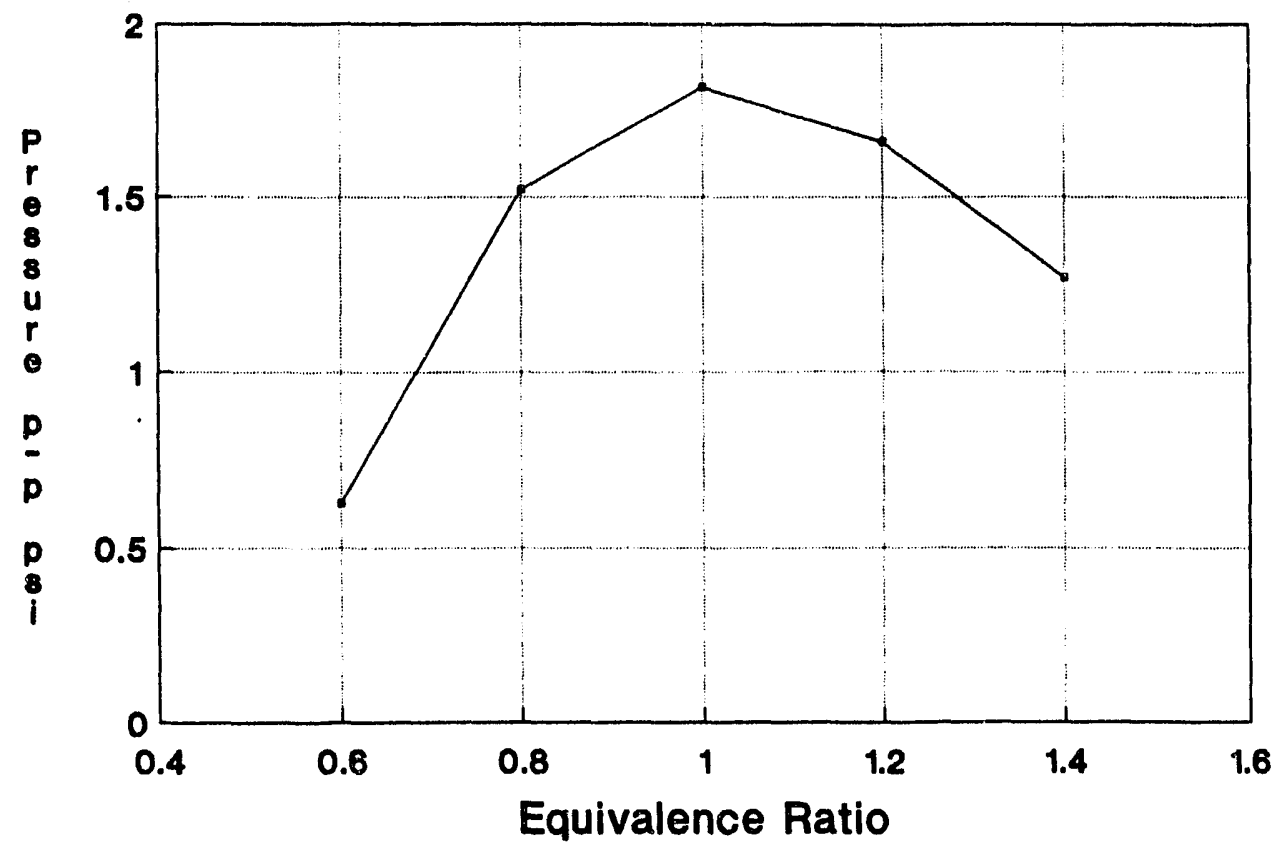

Figure 27. Effect of Equivalence Ratio on Maximum Pressure Excursions for the Propane and Oil Shale Fired Pulse Combustor (Tail pipe $=4 \mathrm{ft}$, $1.22 \mathrm{~m})$.

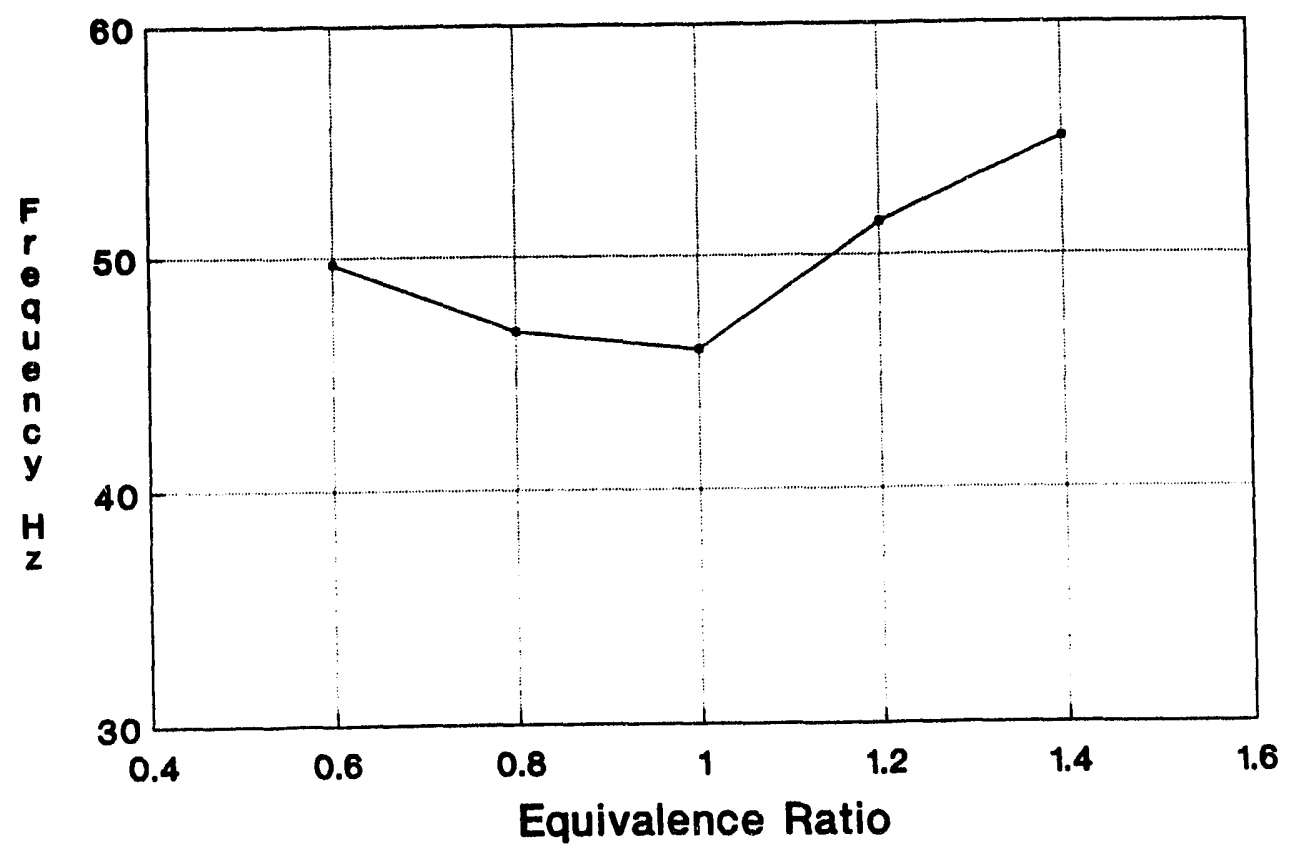

Figure 28. Effect of Equivalence Ratio on Pulsation Frequency for the $1.22 \mathrm{~m}$ ). 


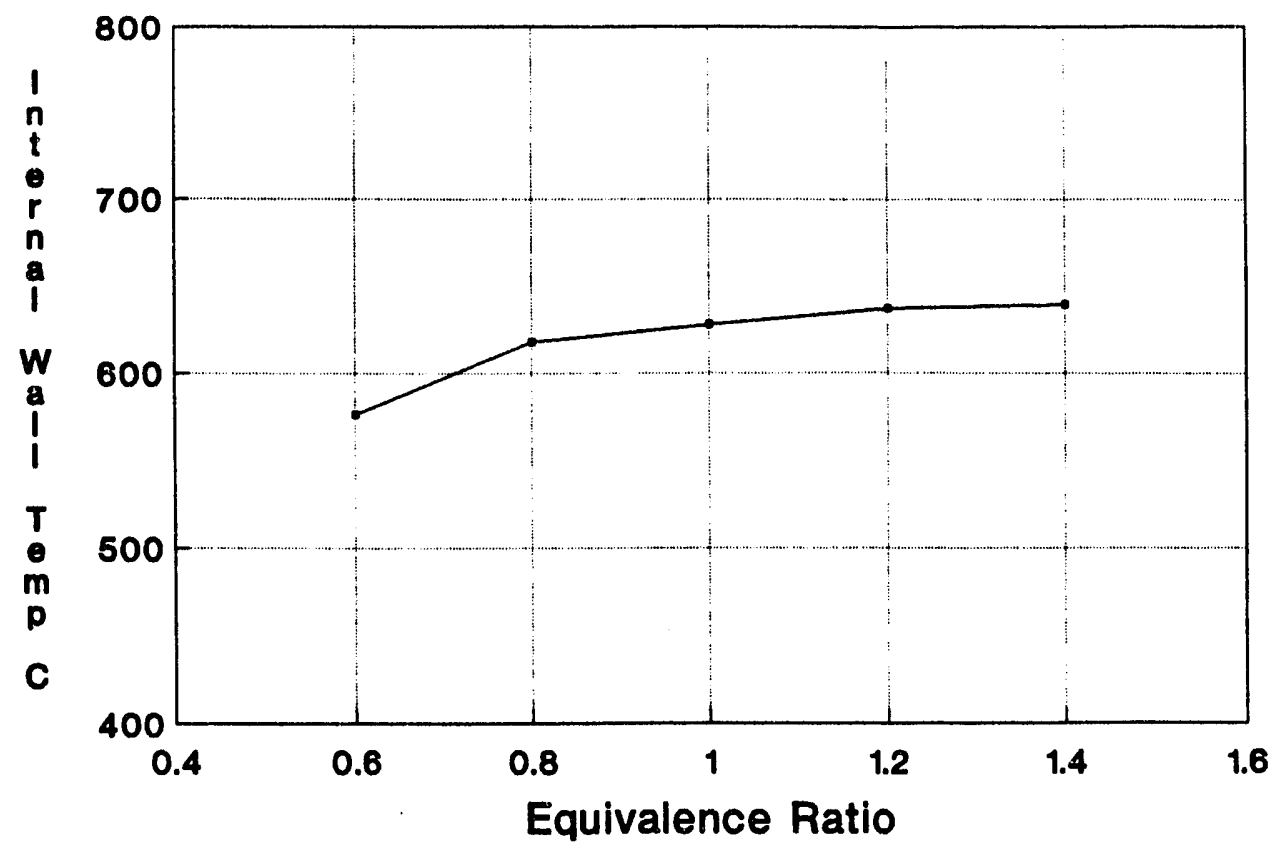

Figure 29. Effect of Equivalence Ratio on the Internal Wall Temperature for the Propane and Oil Shale Fire Pulsed Combustor (Tail pipe $=4$ ft, $1.22 \mathrm{~m}$ ). 


\section{Oil Shale Fuel}

The pulse combustor was preheated by burning propane fuel prior to the oil shale injection. The oil shale was fed via the screw feeder at the rate of $2.88 \mathrm{~kg} / \mathrm{hr}$ along with the propane. After stable operating conditions were established in the combustor based on the combustor temperature and pressure trace, the propane flow was turned off. The combustor continued to burn the oil shale, however the pulsations gave way to a steady combustion mode exhibiting a yellow luminous flame. Apparently, the oil shale particles do not burn fast enough to achieve large amounts of energy release while in the combustor volume. The particles continue to burn in the tail pipe of the combustor. The addition of trace amounts of propane to the oil shale fuel feed enabled the pulsations. After operating the combustor for a few minutes with oil shale only as fuel, the fuel feed was terminated and the combustor was opened. Spent and unspent oil shale had accumulated within the combustor, indicating that with the presence of pulsations, the flow through the combustor was insufficient to fully convey the solids out of the combustor at this feed rate. No LDA velocity data acquisition was possible for the oil shale tests due to the film coating on the optical access. Several attempts to alleviate the problem proved fruitless. 


\section{CONCLUSIONS}

Pulverized oil shale cannot maintain pulsations in the type of pulse combustor tested without the presence of some amount of gaseous fuel such as propane. Without pulsations, the horizontally mounted combustor could not convey the $5 \mu \mathrm{m}$ oil shale particles out of the combustion chamber for fuel rich or lean conditions. When mixed with propane, the oil shale was able to burn in the combustion chamber and tail pipe yielding up to $80 \%$ of the its organic material to the combustion process. Stable combustion was achieved for both fuel lean and fuel rich stoichiometries for co-fired tests with the two foot $(0.61 \mathrm{~m})$ tail pipe and for stoichiometric and fuel rich test for with the four foot $(1.22 \mathrm{~m})$ tail pipe. The cycle resolved laser Doppler anemometry measurements revealed large differences in outlet flow compared to the reverse inlet flow in the tail pipe. Injecting inert mineral matter (limestone) into the pulse combustor while using propane fuel had only a slight effect on the pulsation frequency for the feed rates tested. 


\section{REFERENCES}

1. Belter, J.W., Dockter, L., and Ellman, R.C., "Operating Experience with Lignite-Fueled Pulse-Jet Engines," ASME Paper 69-WA/FU-4, 1969.

2. Zinn, B.T., Miller, N., Carvalho, Jr.. J.A., and Daniel, B.R.,"Pulsating Combustion of Coal in a Rijke Type Combustor," Proceedings of the 19th International Symposium on Combustion, pp. 1197-1203, 1982.

3. Katsnel'son, B., Marone, I., and Tarakanovskii, A.,"An Experimental Study of Pulsating Combustion", Thermal Engineering, Vol. 16, 1969.

4. Carvalho, Jr. J.A., Wang, M.R., Miller, N., Daniel, B.R., and Zinn, B.T.,"Controlling Mechanism and Performance of Coal Burning Rijke Type Pulsating Combustors," Proceedings of the 20th International Symposium on Combustion, pp. 2011-2017.

5. Traenckner, K., "Pulverized-Coal Gasification Ruhrgas Process,", Transactions of the ASME, Vol. 75, pp. 1095-1097, 1953.

6. Durai-Swamy, K., and Warren, D.W., "Pulse Combustion Applications in Waste Processing," Third Annual National Symposium on Incineration of Industrial Wastes," San Diego, CA, March, 1989.

7. Sommers, H., "Experiences with Pulsating Tube Firing in an Experimental Installation," from Pulsating Combustion, the Collected Works of F.H. Reynst, M.W. Thring, Editor, Pergamon Press, 1961.

8. Powell, E.A., Zinn, B.T., Narayanaswami, L.L., and Daniel, B.R., "Pulsating Gasification of Low-Rank Coals," Final Report prepared for the U.S. Department of Energy under Contract No. DE-AC18-84FC10620.

9. Richards, G., Morris, G., Shaw, D., Keeley, S., and Welter, M.,"Thermal Pulse Combustion", presented at the International Symposium on Pulse Combustion, Monterey, CA, August, 1991.

10. Morris, G., "An Experimental Investigation of the Motion of Solid Particles in a Fluidically Oscillating Jet", Ph.D. Dissertation, West Virginia University, 1985. 
APPENDIX A - Test Conditions for the Propane Fired Pulse Combustor Experiments

Table A.1 Test Conditions for the Four Foot $(1.22 \mathrm{~m})$ Tail Pipe.

\begin{tabular}{|c|c|c|c|c|}
\hline$\phi$ & $\begin{array}{l}\text { Propane Flow } \\
\text { liter/min }\end{array}$ & $\begin{array}{l}\text { Air Flow } \\
\text { liter/min }\end{array}$ & $\begin{array}{l}\text { Wall Temp. } \\
{ }^{\circ} \mathrm{C}\end{array}$ & $\begin{array}{l}\Delta \mathrm{P}_{\text {max }} \\
\mathrm{kPa}\end{array}$ \\
\hline 0.6 & 4.70 & 188.80 & 521 & 11.2 \\
\hline 0.8 & 6.30 & 188.80 & 635 & 8.98 \\
\hline 1.0 & 7.91 & 188.80 & 596 & 8.98 \\
\hline 1.2. & 9.56 & 188.80 & 571 & 8.70 \\
\hline 1.4 & 11.1 & 188.80 & 562 & 9.72 \\
\hline
\end{tabular}

Table A.2 Test Conditions for the Two Foot $(0.61 \mathrm{~m})$ Tail Pipe.

$\begin{array}{llllll}\phi & \begin{array}{c}\text { Propane Flow } \\ \text { liter/main }\end{array} & \begin{array}{c}\text { Air Flow } \\ \text { liter/min }\end{array} & \begin{array}{c}\text { Wall Temp. } \\ { }^{\circ} \mathrm{C}\end{array} & \begin{array}{l}\Delta \mathrm{P}_{\max } \\ \mathrm{kPa}\end{array} & \begin{array}{l}\text { Freq. } \\ \mathrm{Hz}\end{array} \\ 0.6 & 4.70 & 188.80 & 491 & 12.6 & 66.7 \\ 0.8 & 6.30 & 188.80 & 555 & 11.2 & 74.1 \\ 1.0 & 7.91 & 188.80 & 608 & 10.3 & 77.5 \\ 1.2 & 9.56 & 188.80 & 603 & 10.5 & 81.3 \\ 1.4 & 11.1 & 188.80 & 582 & 10.5 & 77.5\end{array}$


APPENDIX C - Colorado Oil Shale Properties

Dry Basis (weight \%) $\quad$ Organic Material $21 \%$

Mineral Mater $79 \%$

Dry Mineral Matter Free Basis (weight 7.)

C $81.36 \%$

H 9.69\%

N $1.63 \%$

S $1.35 \%$

O 5.98\%

Particle Density $=1.89 \mathrm{~g} / \mathrm{cc}$

Heating Value $=1,828 \mathrm{kcal} / \mathrm{kg}$ 

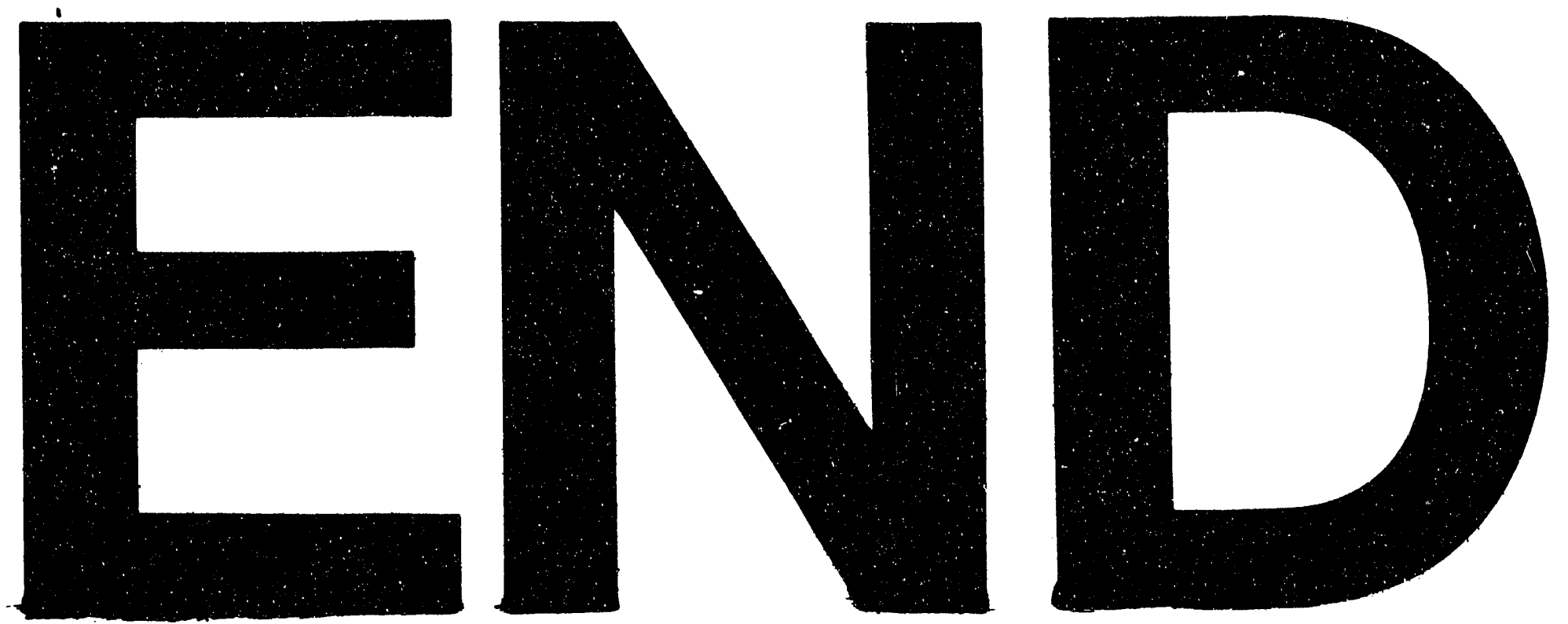

15

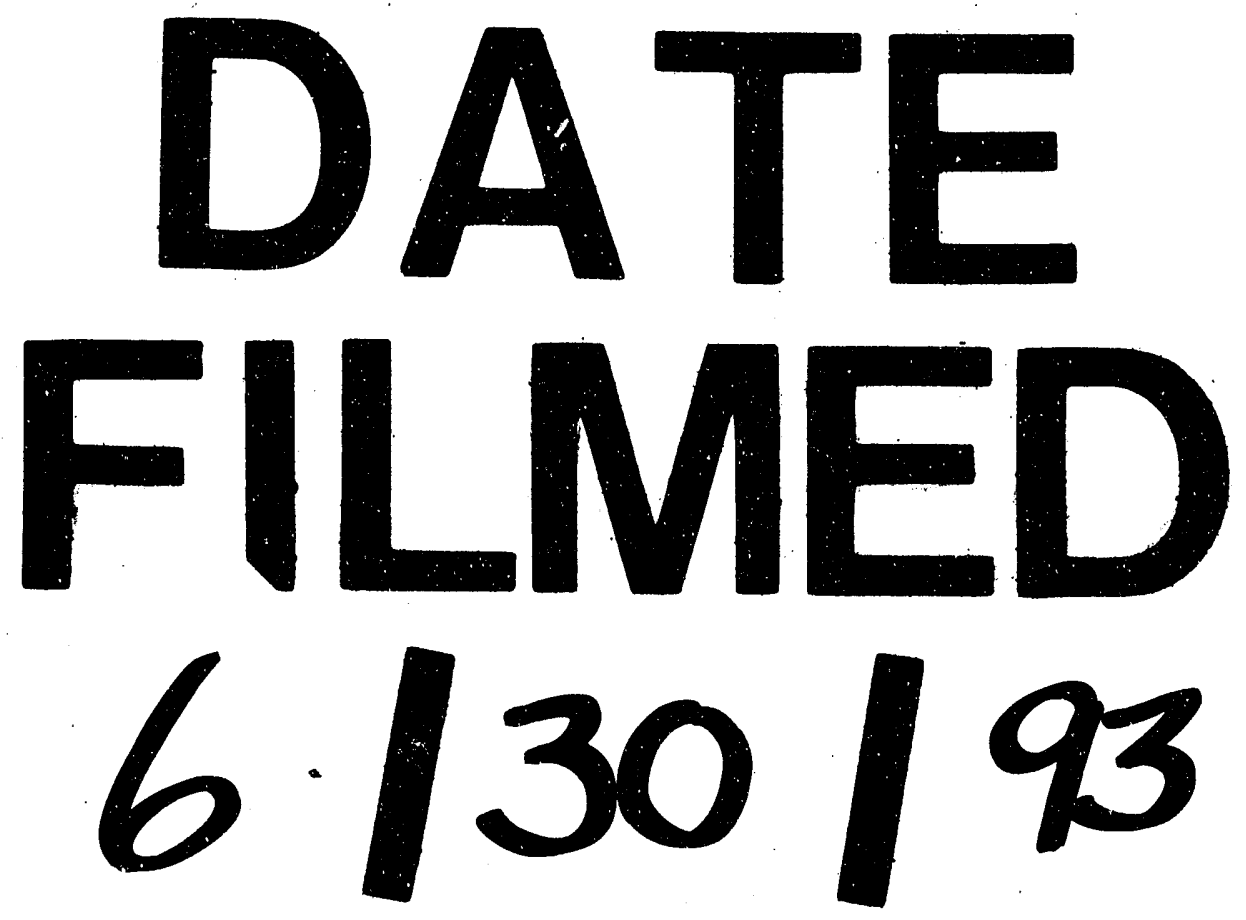


